\title{
PAISAJES PREHISPÁNICOS INTERSTICIALES: NATURALEZA URBANA Y PATRIMONIO ARQUUEOASTRONÓMICO EN ÑAÑA, LIMA ${ }^{(*]}$
}

\author{
INTERSTITIAL PRE-HISPANIC LANDSCAPES: URBAN NATURE AND ARCHAEOASTRONOMICAL \\ HERITAGE IN ÑAÑA, LIMA \\ JUAN MANUEL DEL CASTILLO CÁCERES ${ }^{(\star x)}$ Y PERCY SOPLA BECERRIL ${ }^{(* \star x}$ \\ Universidad Peruana Unión (Perú) \\ juandelcastillo@upeu.edu.pe@ percysopla@upeu.edu.pe \\ Fecha de recepción: 02 de julio de 2018 \\ Fecha de aprobación: 05 de octubre de 2018
}

\begin{abstract}
RESUMEN
El propósito de esta investigación es analizar el paisaje y el patrimonio arqueoastronómico de Ñaña, Lurigancho-Chosica, que sobrevive en los intersticios de la periferia urbana contemporánea de Lima, Perú. La zona arqueológica Unión-Ñaña estuvo habitada desde tiempos prehispánicos por especialistas en la observación de fenómenos celestes llamados yañac, ligados al culto al nevado Pariacaca, el apu más importante de los Andes centrales del Perú, según el mítico Manuscrito de Huarochirí**** del siglo XVI. Por lo tanto, el estudio de la relación entre paisaje y alineamientos astronómicos (un aspecto clave de la cosmovisión andina) formó parte fundamental de la presente investigación, que también tiene el objetivo de profundizar el entendimiento de la función primigenia y potencial a futuro de estos parajes milenarios vinculados al Qhapaq Ñan del Valle del Rímac. El empleo de un enfoque multidisciplinario de investigación, que ahonde en estos hallazgos y sirva como base para el futuro desarrollo ambiental y cultural de la zona de estudio, surge como variable a evaluarse.
\end{abstract}

\section{PALABRAS CLAVE}

Naturaleza urbana, patrimonio arqueoastronómico, paisaje prehispánico intersticial

\section{ABSTRACT}

The objective of this research is to analyse the landscape and archaeoastronomical heritage of Ñaña, Lurigancho-Chosica, in the interstices of the contemporary urban periphery of Lima, Peru. The Union-Ñaña archaeological zone was inhabited since Pre-Columbian times by astronomers called Yañac, linked to the cult of the snow peak Pariacaca, the most important Apu from the Central Andes of Peru, according to the mythical 'Manuscript of Huarochiri' from the 16th century. For this reason, the study of the relationship between landscape and astronomical alignments (a key aspect of the Andean worldview) is part of the present research. In addition, it provides a better understanding of the function and future potential of these ancient sites associated to the Inca Road Network of the Rimac Valley. The need for more multi-disciplinary research, that deepens these findings and builds the foundations for future environmental and cultural development policies in the study area, appears as a variable to be evaluated.

\section{KEYWORDS}

Urban nature, archaeoastronomical heritage, interstitial pre-Hispanic landscape

(*) El presente trabajo tiene como antecedentes a cursos consecutivos de Diseño Arquitectónico y Planeamiento Urbano dictados entre 2015-2017 en la UPeU; los proyectos de investigación "Paisajes intersticiales en el Valle del Rímac: Ecosistemas urbanos y patrimonio arquitectónico andino en Ñaña", 2016, y“Sistemas territoriales precolombinos del Valle del Rímac: Patrones arquitectónicos, observatorios estelares y peregrinaciones andinas en Ñaña", 2017, en UPeU; el artículo "Espacios Abiertos y Patrimonio Arquitectónico Originario en Ñaña", revista Arkinka 2016; y la ponencia "Hybrid Interstices in Metropolitan Borders: Open Space, Andean Architectural Heritage and Informal Urbanization in Lima, Peru" en la conferencia anual del Indian Institute of Human Settlements, en Bangalore, India, en 2017. ${ }^{(* *)}$ Arquitecto por la Pontificia Universidad Católica del Perú, magíster con honores en Arquitectura y Urbanismo por la Universidad de Manchester. Docente e investigador principal de la Universidad Peruana Unión (UPeU). Co-autor del libro Memoria Territorial y Patrimonial: Artes y Fronteras (2014). Su trabajo explora el campo de los paisajes incas y preincas, el patrimonio arqueoastronómico, y los futuros urbanos. Fue miembro del equipo territorial del PLAM 2035. $\left.{ }^{(* * *}\right)$ Bachiller en Arquitectura por la UPeU. Experiencia en investigación en urbanismo y arqueoastronomía, que incluye participación en proyectos de investigación en la UPeU, y colaboración con el instituto ICHMA y el Ministerio de Cultura. Actualmente desarrolla investigaciones sobre patrimonio arqueológico en Lima Metropolitana e integra el equipo de Geo-ciencia de la UPeU.

(****) Aquí se emplea la traducción realizada por J. M. Arguedas, Dioses y Hombres de Huarochirí: Narración Quechua Recogida por Francisco de Ávila (2da edición). (2012). Lima, Perú: Instituto de Estudios Peruanos. 
El paisaje de Ñaña es un caso representativo de los intersticios generados entre estribaciones andinas, zonas arqueológicas y áreas de expansión urbana en los bordes metropolitanos de Lima. Recorrer estos espacios significa experimentar un marcado contraste ante la alternancia de áreas semi rurales, modernas instalaciones educativas, precarias invasiones de terrenos públicos y parajes míticos relacionados al Manuscrito de Huarochirí. Estos paisajes intersticiales son resultado, por una parte, de la presión ejercida desde el área urbana para absorber los remanentes de áreas agrícolas y quebradas inhóspitas en la periferia (sea por medios legales o ilegales). Por otro lado, las aspiraciones de los propietarios rurales por incorporarse a la vida urbana, así como la falta de control y planificación estatal en espacios abiertos son también factores que influyen en la producción de estos paisajes (Silva, 2017). Sin embargo, a pesar de la confluencia de estos elementos dispares, el enorme potencial del contexto geográfico y cultural de la zona arqueológica Unión-Ñaña, que tiene una historia de casi 4,00 años, permanece poco explotado (Palacios, 2013).

Por otro lado, la asociación del lugar a los míticos astrónomos prehispánicos llamados yañac (Taylor, 2008) llevó a explorar las posibilidades del lugar como punto estratégico de observación del cielo. A través del trabajo de campo y registro sistemático de los elementos que conforman el paisaje de Ñaña, durante esta investigación se fue comprobando la importancia de la función astronómica en los sitios arqueológicos de la zona, a la vez que aparecieron nuevas lecturas sobre su potente marco geográfico/ natural y el potencial científico que alberga. Ante este escenario, surge la posibilidad de llevar a cabo más investigaciones de carácter multidisciplinario que puedan aportar al conocimiento sobre estas áreas, el paisaje del que forman parte y la manera más efectiva de integrarlas al contexto social en el que se encuentran.

Durante este estudio, se utilizó el trabajo de campo como elemento activo y constante de corroboración de los hallazgos obtenidos mediante la revisión bibliográfica de textos históricos. Para el registro del contexto espacial se utilizaron mapas, esquemas gráficos y fotografías, mientras que para el estudio de la relación entre paisaje y arqueoastronomía se realizó la observación directa del cielo nocturno en fechas claves para la cosmovisión andina, con el apoyo de los software Stellarium y SunCalc (ambos de acceso libre) para la comprobación de alineaciones astronómicas, y el software ARC GIS y el instrumento GPS Garmin Etrex 30x para obtener las geolocalizaciones.

En cuanto a los antecedentes, es importante resaltar el trabajo del reconocido investigador y arqueólogo Jonathan Palacios, quien ha contribuido activamente a la investigación de la zona Unión-Ñaña. Palacios ha publicado los textos Proyecto Arqueológico Unión-Ñaña: Informe final en 2000; La Fortaleza del Cerro Cuncacucho: Naña, Valle Medio del Rímac en 2013, y Agua. Ritual y Culto en Yañac (Ñaña): La Montaña Sagrada en 2017, todos bajo el auspicio de la Universidad Peruana Unión (UPeU). Por otro lado, la presente investigación se nutre de una base de datos que ha sido construida durante una serie de cursos sucesivos de la Escuela de Arquitectura UPeU' y dos proyectos de investigación auspiciados por la Dirección General de Investigación de la misma universidad².

Finalmente, cabe mencionar la divulgación de los resultados preliminares de la investigación, en el artículo "Espacios Abiertos y Patrimonio Arquitectónico Originario en Ñaña", publicado en la revista Arkinka en 2016, y en la presentación de la ponencia

\footnotetext{
1. Diseño Arquitectónico IV, semestre 2015-1; Diseño Arquitectónico V y Seminario de Planeamiento Urbano, semestre 2015-2; Seminario de Planeamiento Urbano, semestre 2016-1; y Planeamiento Urbano V, semestre 2017-1.

2. Paisajes Intersticiales en el Valle del Rímac: Ecosistemas Urbanos y Patrimonio Arquitectónico Andino en Ñaña, en 2016, y Sistemas Territoriales Precolombinos del Valle del Rímac: Patrones Arquitectónicos, Observatorios Estelares y Peregrinaciones Andinas en Ñaña, en 2017.
} 
"Hybrid Interstices in Metropolitan Borders: Open Space, Andean Architectural Heritage and Informal Urbanization in Lima, Peru" en la conferencia anual del Indian Institute of Human Settlements, en Bangalore, India, en 2017.

\section{Los bordes metropolitanos como espacio de encuentro entre naturaleza, patrimonio y urbanización}

Los bordes metropolitanos son generalmente considerados espacios duales, que cuentan con atributos naturales que atraen a la ciudadanía pero a la vez generan en ella cierta desconfianza, pues se les considera espacios abandonados (Jorgensen \& Tylecote, 2007). Sin embargo, durante los últimos años ha surgido en las áreas metropolitanas latinoamericanas una mezcla única de paisajes espontáneos que constituyen un claro símbolo de las posibilidades urbanas: "Ellos revelan una ciudad dentro de otra ciudad que no se manipula para el turismo o el consumo, sino que está abierta a diversas alternativas; una red de espacios no regulados dentro de los cuales tanto la diversidad ecológica como sociocultural puede florecer" (Gandy, 2011, p. 152). En el presente texto se llamará a estos espacios paisajes intersticiales.

Aunque la investigación sobre paisajes de borde entre ciudad, estribaciones andinas y patrimonio prehispánico en el Perú se encuentra aún en un estado incipiente, durante las últimas décadas (que coinciden con la expansión de las principales ciudades del Perú) ha comenzado a aparecer literatura científica que aborda aunque sea de forma tangencial la realidad de su problemática. En el caso de Lima, si bien es cierto que las investigaciones sobre biodiversidad en cerros y lomas costeras existen desde fines del siglo XVIII (Zeballos, Villegas, Gutiérrez, Caballero \& Jiménez, 2000), poco ha sido escrito sobre la problemática de su gestión ambiental. Entre los estudios que han explorado ese campo cabe destacar dos trabajos de Padilla: el informe de prácticas pre-profesionales Lomas de Mangomarca, Campoy y El Sauce: Estudio de Caso (2012) y la tesis de pregrado Estudio de la Variación Espacio-temporal de la Comunidad Vegetal de las Lomas de Mangomarca durante el año 2013 como Contribución a su Gestión (2017). En estos textos se hace referencia a los servicios ecosistémicos que las lomas pueden brindar a la sociedad urbana; se identifica los actores, las dinámicas ecológicas, el potencial y las debilidades que deben tomarse en cuenta a futuro para su manejo. En ese sentido, el entendimiento del concepto de ecosistema urbano puede brindar mayores alcances para abordar estas nuevas problemáticas.

Los ecosistemas urbanos se originan como consecuencia de procesos de urbanización en los cuales interactúan los componentes sociales, biológicos y físicos de la ciudad, y que implican la conversión de áreas rurales u otro tipo de áreas por efecto del crecimiento poblacional y/o de la expansión del espacio urbano (Nilon, Berkowitz \& HoIlweg, 2003). La conversión resultante de terrenos salvajes o rurales en suelo urbano generalmente produce una reducción en la diversidad de flora y fauna nativa, aunque existen excepciones a este patrón, ya que los humanos crean continuamente comunidades biológicas en sus jardines, parques, pastos y suelos institucionales (Szlavecz, Warren \& Pickett, 2011). Además de la comprensión de este concepto, es importante el análisis de las características de los ecosistemas urbanos en el contexto andino y americano, pues puede aportar al debate a nivel global.

El territorio de Lima, además de poseer una rica estructura ecológica conformada por áreas naturales (lomas, ríos, humedales, valles agrícolas y litoral marino) que necesitan ser incorporadas a una red metropolitana de espacios abiertos públicos para protegerlas del avance de la urbanización informal, alberga una gran cantidad de sitios arqueológicos prehispánicos, los cuales antiguamente en la mayoría de casos demarcaban los límites entre las áreas habitada y natural, y forman hoy en día gran parte del patrimonio cultural de la región (Del Castillo, 2016). Se entiende por patrimonio cultural a un conjunto de elementos susceptibles de ser estimados por un ente social 
en tanto testimonios de la actividad humana, y comprende al conjunto de actuaciones programadas para optimizar su conservación y uso adecuado a las exigencias sociales contemporáneas (Hayakawa, 2010).

En cuanto a la noción de patrimonio arqueoastronómico, esta hace referencia a entes patrimoniales que tienen tanto valor arqueológico como astronómico. Cabe resaltar que si bien el término arqueoastronomía no ha sido reconocido aún por la Real Academia de la Lengua Española, se trata de una disciplina en pleno crecimiento (Salazar, 2014). Muestra de ello es la aparición reciente de reveladores estudios en esta rama, que aportan nuevas perspectivas y abren nuevas alternativas para la investigación de sitios arqueológicos prehispánicos preincas e incas, como en el caso de Chankillo en Casma, Perú (McKim Malville, 2011); el Shincal de Simivil en Catamarca, Argentina (Giovannetti, 2015); e Inkaraqay - El Mirador en Cusco, Perú (Astete Victoria, Ziółkowski \& Kościuk, 2017). Entre este tipo de investigaciones, el estudio sobre el paisaje y sitio arqueológico de Chankillo, publicado en la revista Science, es revelador sobre la observación del paso del sol a lo largo del año, que se realizaba con ayuda de 13 torres de piedra, y servía para determinar un calendario andino que permitía organizar las principales actividades agropecuarias y las fiestas asociadas (Ghezzi \& Ruggles, 2007). Este caso fue de particular interés para el presente estudio, debido a la existencia comprobada de antiguos especialistas en la observación del cielo, que ocupaban un rol preponderante en su sociedad y ordenaban la construcción de elementos arquitectónicos con dimensiones precisas para la medición de fenómenos celestes, al igual que en Ñaña.

Así mismo, el libro Astronomía Inka de Erwin Salazar Garcés es un aporte significativo, pues elabora una síntesis de las principales características de la arqueoastronomía y etnoastronomía, entre ellas los métodos empleados, las constelaciones registradas y las fiestas importantes vinculadas a la observación astronómica en tiempos del Tawantinsuyu (Salazar, 2014).

En general, en los estudios antes mencionados se logró comprobar la alineación de estructuras prehispánicas con fenómenos astronómicos, así como su importancia en la cosmovisión andina, mediante la combinación de trabajo de campo, observación estelar y el uso de aparatos de medición digital.

Por otro lado, el papel actual que cumple el patrimonio arqueológico periurbano en el desarrollo del Perú genera más preguntas que respuestas. En el caso de la capital, según el Plan Metropolitano de Desarrollo Urbano Lima-Callao al 2035, el patrimonio arqueológico prehispánico está conformado por 538 monumentos (495 ubicados en Lima y 43 en el Callao). De estos, solo 257 han sido delimitados por el Ministerio de Cultura, mientras que del resto solo se conoce su ubicación. Entre aquellos delimitados, solo 26 han sido puestos en valor, mientras que únicamente 10 (la mayoría ubicados en zonas céntricas de Lima) cuentan con instalaciones aptas para recibir visitas (Municipalidad Metropolitana de Lima, 2014; Guzmán Requena, 2018). Las áreas interdistritales de Lima Este (52) y Lima Norte (38) presentan la mayor cantidad relativa de conjuntos edificados, los cuales se encuentran en estado de abandono, pero en su mayor parte se conservan completos. Su supervivencia resulta más factible debido a su lejanía del continuum urbano, pues se ubican en las periferias, en los valles de los ríos Chillón, Rímac y Lurín. Consecuentemente, la habilitación turística (estrategia principal del Estado Peruano frente al patrimonio) de las más de 250 áreas arqueológicas ubicadas en la periferia de Lima es poco realista a corto y mediano plazo (Municipalidad Metropolitana de Lima, 2014).

Frente a este panorama, es interesante encontrar vestigios de arquitectura ceremonial que se remontan hasta épocas tan antiguas como el Formativo (Canziani, 2009). Es este el caso de uno de los nueve complejos patrimoniales más grandes de todo Lima, situado al este de la ciudad, en el distrito de Lurigancho-Chosica: la zona arqueológica Unión-Ñaña, que cuenta con 313.56 hectáreas de extensión (Municipalidad Metropo- 


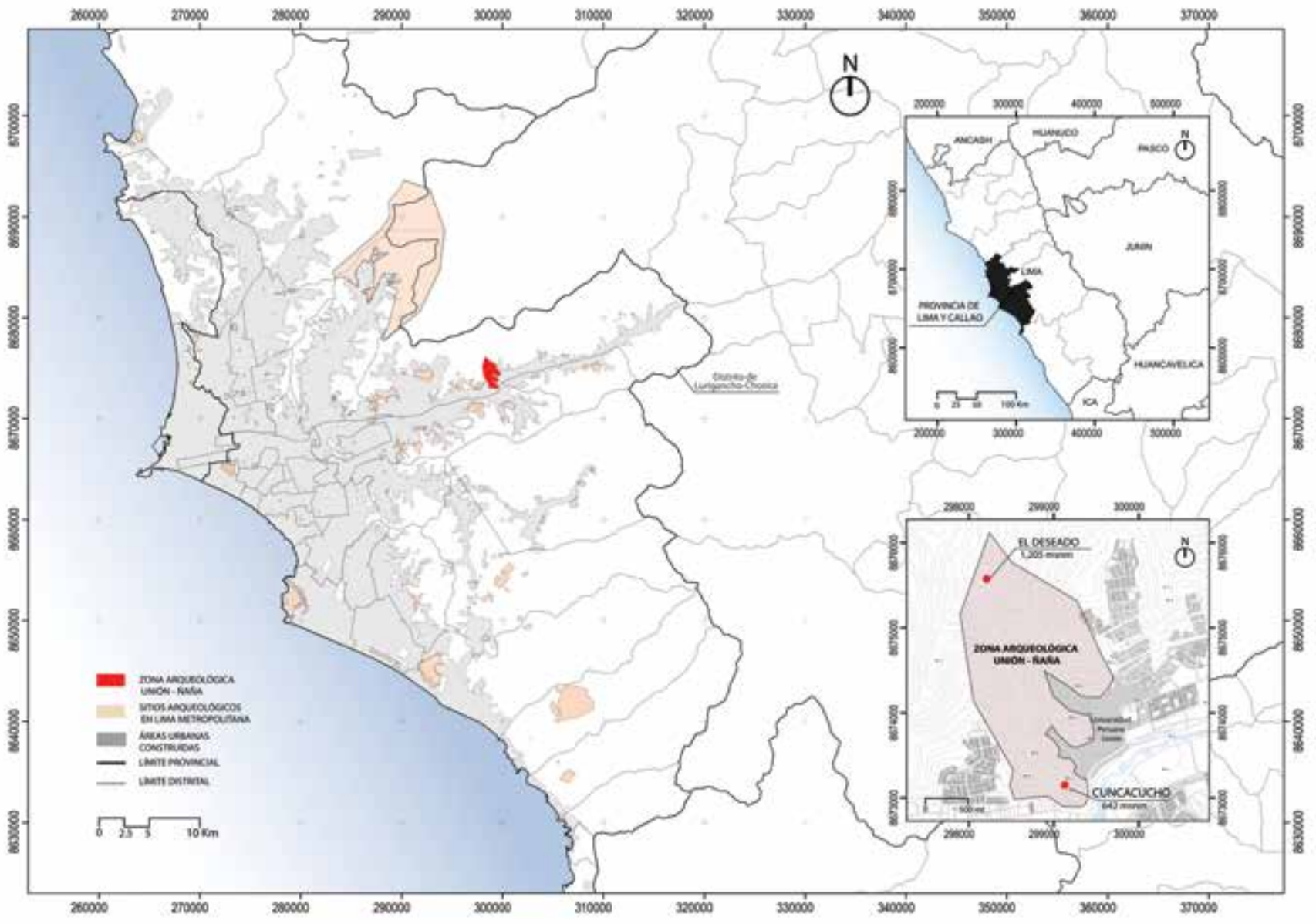

litana de Lima, 2014). Sin embargo, aún no existen investigaciones sobre paisajes intersticiales, o de borde entre ciudad y naturaleza en la localidad de Ñaña, por lo que resulta oportuno resaltar la existencia de restos patrimoniales, entre la Universidad Peruana Unión y los cerros que la circundan (Palacios, 2017). Por otro lado, es importante entender el territorio de Ñaña como parte de un paisaje ancestral que guarda las huellas de sus habitantes desde tiempos prehispánicos. Allí, las culturas preinca e inca realizaron obras de arquitectura, infraestructura de caminos, canales de riego y terrenos agrícolas; produjeron cerámica, y conocimientos de domesticación de plantas y animales; todo en equilibrio armónico con el medio geográfico, información útil para elaborar estrategias de desarrollo sostenible a futuro.

\section{El paisaje milenario de los yañac y su ocupación a través del tiempo}

"Son maestros, uno o dos de ellos, a quienes se les denomina yañca en todos los pueblos, él, desde un muro bien construido, mira el caminar del sol, y en cuanto el sol llega al muro, vocea a la gente y les dice si deben ir ese día o al día siguiente. Y siguiendo al yañca los hombres van a adorar a Pariacaca." (Arguedas, 2012, p. 65)

Con estas palabras, en la primera aparición de los yañca o yañac (topónimo que luego derivaría en el actual Ñaña) en el Manuscrito de Huarochirí, se describe cómo la divinidad andina Pariacaca encarga a estos maestros astrónomos y constructores la determinación del día en que los pueblos le rendirían culto, subiendo en peregrinación hasta el nevado que lleva el nombre de este apu o montaña sagrada.
Figura 1. Ubicación de la zona arqueológica Unión-Ñaña y el cerro Cuncacucho. Elaborado por J. M. Del Castillo \& P. Sopla, sobre la base de archivos shapefile-ArcGIS del Ministerio de Cultura y el Instituto Geográfico Nacional (IGN). El registro de altitud en El Deseado fue tomado con GPS Garmin Etrex 30x. 
Estos especialistas rituales habitaban la cima del cerro Cuncacucho, el cual se encuentra en la actual localidad de Ñaña, al ingreso del valle medio del Rímac, en la margen derecha, a 642 m s. n. m. y a 34 kilómetros del litoral, en el piso ecológico yunga (Palacios, 2013) (Figura 1).

La ocupación de este cerro se remonta hasta el formativo (1800 a 1500 a. C.), cuando se construyeron en las faldas del mismo estructuras efímeras de quincha o carrizos entretejidos. Posteriormente, en la época denominada cerro (200 a. C. a 100 d. C.), se ocupó la meseta de Cuncacucho, al parecer como respuesta ante la existencia de amenazas invasoras, pero también debido al activo trueque que mantenían con otras sociedades del litoral y la sierra. Entre los años 200 y 400 d. C., tuvieron lugar enfrentamientos con grupos humanos de los alrededores que propiciaron la realización de una serie de obras defensivas, como el amurallado perimetral de la actual fortaleza del cerro, mientras que en el resto del valle las poblaciones vecinas cavaron trincheras (Palacios, 2013). En los restos pertenecientes al periodo comprendido entre los años 400 y 600 d. C., se puede apreciar la influencia de la cultura Lima en la zona: se construyó una plataforma de adobe, pintada de amarillo y rojo, al centro de la fortaleza. Luego, entre 900 y 1470 d. C., estos territorios pasaron al dominio de la cultura ichmay; en dicho periodo se construyó una serie de asentamientos ortogonales con tapial. Tras la conquista inca, entre 1470 y 1533 d. C., se llevó a cabo una reorganización política y económica, y se construyeron sedes administrativas en tapial en la falda del cerro, hacia el lado este ( $\mathrm{Pa}$ lacios, 2013). Finalmente, tras la invasión española, como consecuencia del proceso de extirpación de idolatrías que se llevó a cabo, el sitio fue gradualmente abandonado. Así, los pueblos originarios de Lurigancho, Tantacaxa y Yauyos figuran en un censo de 1549 como encomendados al arzobispo de Lima, Gerónimo de Loaysa (Rostworowski, 1990).

Durante la Colonia y hasta la República, las tierras de Ñaña continuaron siendo parte de los fundos de Lurigancho, de cuyas tierras diferentes hacendados tomaron posesión. La función principalmente agrícola de estas tierras se mantuvo prácticamente inalterada hasta 1945, cuando el Colegio Unión trasladó sus instalaciones a Ñaña. El terreno sobre el que se posicionó serviría años más tarde, en 1983, como campus para la recién fundada Universidad Unión Incaica, cuya inauguración dio inicio a la transformación urbana de Ñaña. En 1995, esta universidad se convirtió en la UPeU (Castillo, 2010), casa de estudios que en 2015 albergaba a una comunidad académica de 4,239 personas (entre estudiantes y trabajadores), la cual representaba casi la cuarta parte de la población total de Ñaña (18,664 habitantes) y constituía el núcleo principal de la localidad.

\section{Espacios intersticiales y urbanización: Problemática actual y posibilida- des en Ñaña}

En el contexto actual, el Cerro Cuncacucho y la zona arqueológica Unión-Ñaña ocupan un espacio intersticial entre el continuum urbano (hacia el Sur), y las estribaciones andinas (hacia el Norte) que lo contienen y anuncian la predominancia de la estructura ecológica de Lima a medida que se avanza hacia el Este (Del Castillo, 2016). Si bien es cierto, por un lado, que el creciente reconocimiento de los valores estéticos y científicos de espacios hasta hace poco considerados "residuales" ha hecho notoria la independencia de la actividad natural dentro del diseño urbano (Gandy, 2011), por el otro, la realidad del desenfrenado crecimiento ilegal de los bordes de Lima, debido al gran déficit de programas eficientes de vivienda popular que experimentan otras grandes ciudades del Perú, se expresa también en Ñaña, donde se ha convertido en una amenaza latente ante la total ausencia de planificación y decisión política respecto de estos espacios.

En ese sentido, la ubicación de la universidad ha servido como un resguardo eficiente para el área natural y patrimonial, pues protege espacios geográficos (y la biodiversidad asociada) que permanecen aún inhabitados, y evita que valiosos restos arquitectónicos y arqueológicos sean arrasados por completo por la urbanización (Del Castillo, 


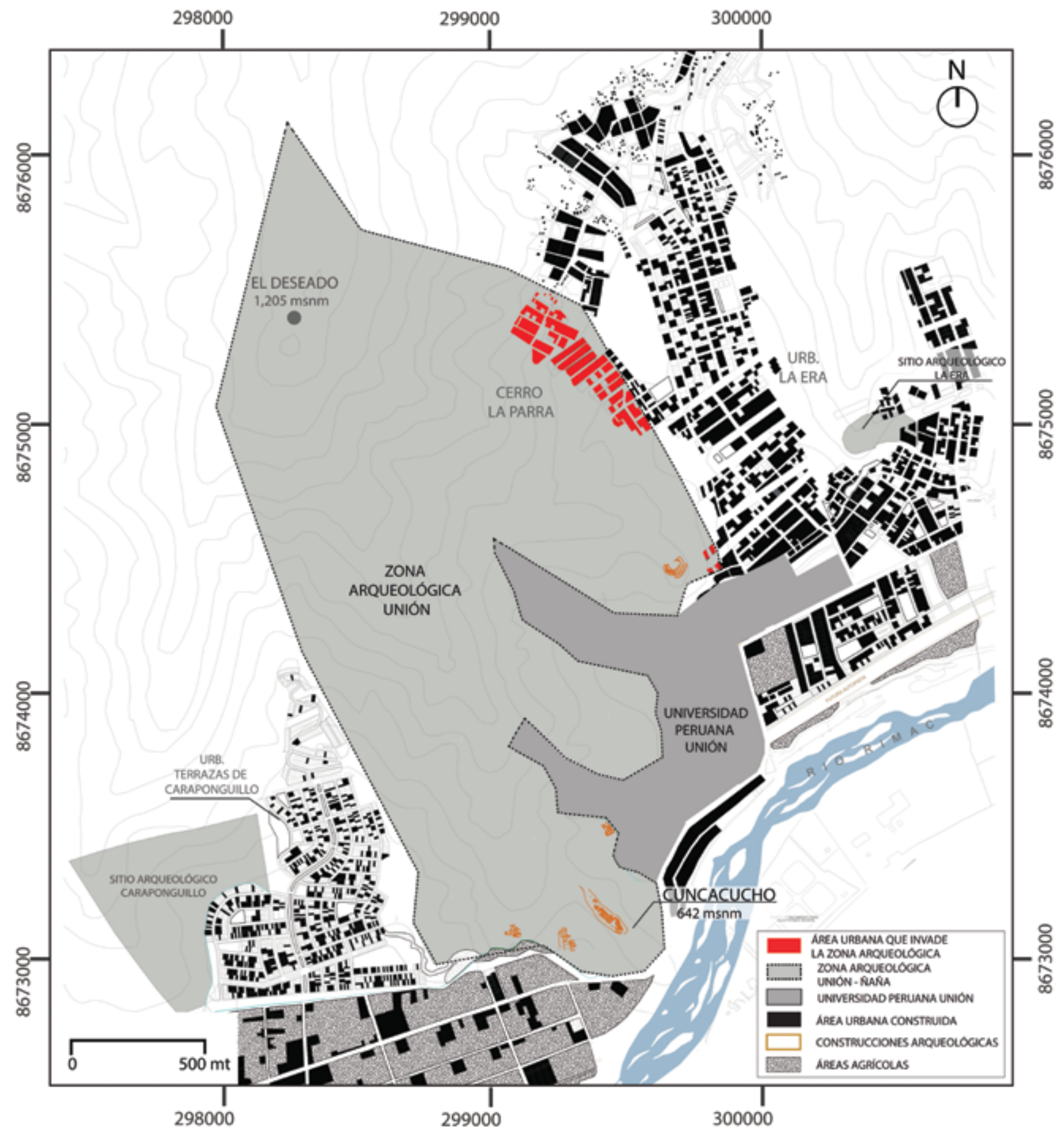

2016). Así mismo, destaca el rol de la universidad (junto al ahora Ministerio de Cultura), que a través de profesionales altamente competentes en su campo ha promovido la realización de estudios (Palacios, 2000), y publicaciones que han posibilitado un mayor conocimiento de esta área y su importancia en la organización territorial de Lima prehispánica, específicamente del valle del Rímac. Ese paisaje ancestral, no obstante alterado, es poseedor de tal potencia en su emplazamiento que basta recorrerlo y subir a sus cimas para transportarse hacia el pasado e imaginarse a los yañac liderando caravanas de antiguos limeños hacia la cumbre del cerro La Parra.
Figura 2. Crecimiento urbano alrededor de la zona arqueológica Unión-Ñaña y cerro La Parra. Editado por J. M. Del Castillo \& P. Sopla, a partir del mapeo de contexto realizado por $\mathrm{L}$. Gonzales, C. Luis \& L. Ignacio, 2018. 
En términos geográficos, su jerarquía como punto de paso hacia el valle medio por el Este y el valle bajo por el Oeste, sumada al accidente geográfico que da nombre al cerro más notorio (Cuncacucho significa "lugar semejante a una garganta" en quechua), donde precisamente se angosta el valle, da una idea muy clara de por qué los antiguos habitantes de estos parajes lo consideraron una posición estratégica, y crearon asentamientos, fortificaciones y complejos ceremoniales en él (Palacios, 2013).

Hoy en día, debido a la ausencia de políticas adecuadas de planeamiento urbano, gestión ambiental y patrimonial, el acceso a la zona es muy limitado, puede accederse solo de forma peatonal, a través de trochas empinadas, desde ciertos puntos en el interior del campus de la universidad (Del Castillo, 2016). A esto se suma que, en las inmediaciones de la urbanización La Era, la más cercana a la zona patrimonial por el Este, el crecimiento en las partes más altas está teniendo lugar sin ningún tipo de habilitación urbana, mediante vías mayoritariamente de tipo trocha. Con el aliciente del Decreto Legislativo N 1202, promovido por el Ministerio de Vivienda (Presidencia de la República, 2015), que legaliza las invasiones de terrenos públicos desocupados hasta el 24 de noviembre de 2010, es muy posible que este crecimiento continúe expandiéndose hacia el Norte, hacia Huarochirí. A fines de noviembre de 2016 tuvo lugar una nueva invasión en los cerros de La Era, promovida por mafias de terrenos, hacia el Este de la zona arqueológica. El asentamiento ilegal se mantiene hasta el momento ante el total desinterés de las autoridades locales y nacionales, lo cual muestra que estos conflictos territoriales están aún lejos de alcanzar una etapa terminal en la zona (Figura 2).

Por otro lado, el contexto natural deja entrever la importancia hidrológica del emplazamiento, desde el cual se tenía control sobre el canal que irrigaba el área de Carapongo hacia la parte baja del valle, que se encuentra ubicado al sur de Cuncacucho (Palacios, 2013). Actualmente, existen una serie de canales modernos que, partiendo desde partes más altas del río, irrigan los alrededores del cerro, probablemente inspirados en los canales prehispánicos o que quizás incluso los reutilizan. Un estudio histórico más exhaustivo podría ofrecer más luces al respecto, así como sobre la ubicación de los caminos prehispánicos que unían la zona aquí estudiada con otras huacas de los alrededores y el Qhapaq Ñan del Rímac. Lo cierto es que la actual infraestructura hidrológica (así como la profusa neblina existente en invierno) propicia la presencia de abundante vegetación en los alrededores del cerro, la cual a su vez atrae a una importante cantidad de fauna conformada por una gran variedad de aves (lechuzas, chihuacos, picaflores, etc.), insectos (abejas, arácnidos, etc.), reptiles (lagartijas y serpientes) y mamíferos (zorros), lo cual contrasta con el carácter más árido de los cerros y sus formaciones rocosas (Del Castillo, 2016).

Así mismo, cabe resaltar que los cerros Cuncacucho y La Parra se encuentran clasificados como lomas costeras extraordinarias (Municipalidad Metropolitana de Lima, 2014), es decir, que son susceptibles de llenarse de vegetación cada vez que tiene lugar el fenómeno del Niño. Se tiene registro de que en el año 1969 los cerros que rodean a la UPeU aún se poblaban de vegetación estacional (Castillo, 2010), razón por la cual atraían gran cantidad de fauna e incluso, en tiempos prehispánicos, ocasionalmente a pumas. Además, entre la flora de estos cerros destacan los tillandsiales, que se caracterizan por agrupaciones de bromeliáceas del género Tillandsia, cuya adaptación a zonas desérticas es asombrosa, razón por la cual reciben el nombre Tillandsias grises (Aguilar \& Turkowsky, 1977). Este tipo de vegetación aún puede registrarse en las montañas de Ñaña, aunque en mucha menor cantidad debido a la acción contaminante de la urbanización. Las tillandsias se ubican principalmente en las laderas que reciben influencia del viento húmedo; debido a la gran cantidad de neblina que se forma en invierno en Ñaña es posible encontrar las especies T. latifolia, T. paleacea, T. purpurea y T. recurvata, entre los 300 y 700 m s.n.m., las cuales en tiempos antiguos posiblemente formaban colchones que cubrían grandes porciones de suelo (Aguilar \& Turkowsky, 1977), mientras que hoy solo existen parches inconexos en distintas áreas. 


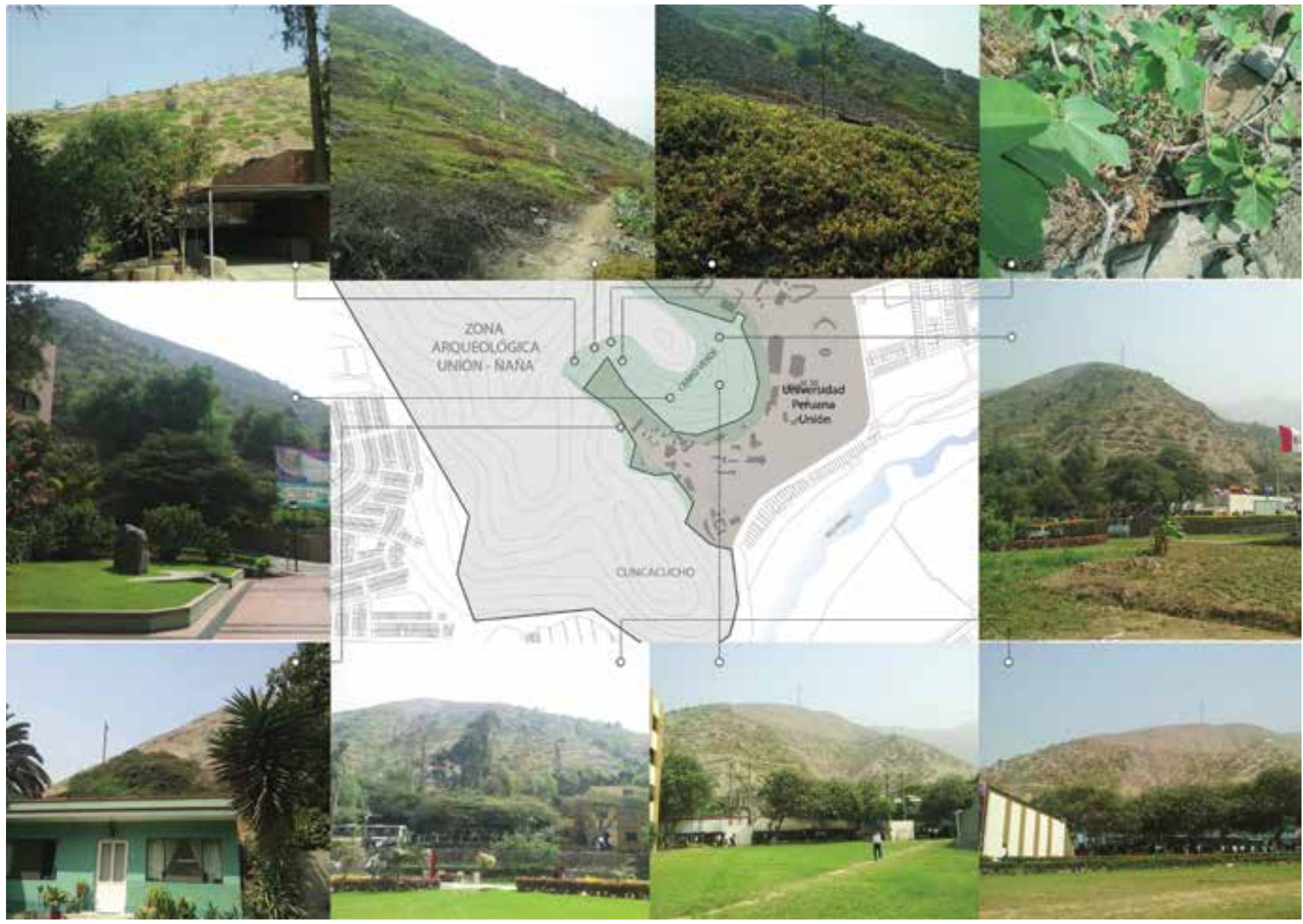

Cabe mencionar que, aproximadamente siete años atrás, la UPeU inició el programa Cerro Verde como parte de sus políticas de regeneración ambiental, en el que mediante un sistema de riego por goteo se introdujo vegetación foránea en el cerro contiguo al norte de Cuncacucho. Si bien es cierto que esta acción ha hecho reverdecer el cerro con algunos árboles frutales, flores y plantas ornamentales, también supone una intervención invasiva en el mismo, que ha desplazado a la flora nativa y los tillandsiales de grandes porciones del cerro. Es un ejemplo claro de una intervención bien intencionada, pero que no tomó en cuenta el contexto ecológico territorial ni el aspecto de planificación a futuro (Figura 3).

Otro punto a resaltar, ligado al pobre entendimiento que se tiene en el Perú de los conceptos de naturaleza urbana y paisaje prehispánico, es la presencia de enormes torres de alta tensión en las cumbres de los cerros, que alteran la vista del entorno y el entendimiento del mismo como parte de un rico proceso histórico con base ancestral (Del Castillo, 2016).

En cuanto al acceso al área arqueológico-natural, la única forma de llegar a esta es mediante trochas que inician en la UPeU, donde existe un acceso vehicular que llega hasta la mitad de la quebrada denominada "Las Tunas", el cual se transforma en un camino peatonal que sube hacia el cerro La Parra. Los accesos peatonales hacia la zona arqueológica han sido creados en su mayoría por personas que visitan el cerro El Deseado, a 1,205 m s.n.m., donde ocasionalmente acampan grupos de niños exploradores de la Iglesia Adventista del Séptimo Día, llamados conquistadores; o por caminantes espontáneos de la comunidad universitaria amantes del trekking o montañismo.
Figura 3. Programa Cerro Verde UPeU. Editado por J. M. Del Castillo \& P. Sopla, a partir de los archivos fotográficos de E. Sencia, A. Iberico, L. Becerra \& F. Allcca, y planos de infraestructura UPeU 2018. 
devenir Vol. 5, N¹0, JULIO-DICIEMBRE 2018, PP. 153-174 - EstudIOS I ISSN 2312-7562 I E-ISSN 2616-4949

UNIVERSIDAD NACIONAL DE INGENIERÍA, LIMA

DOI: https://doi.org/10.21754/devenir.v5i10.603

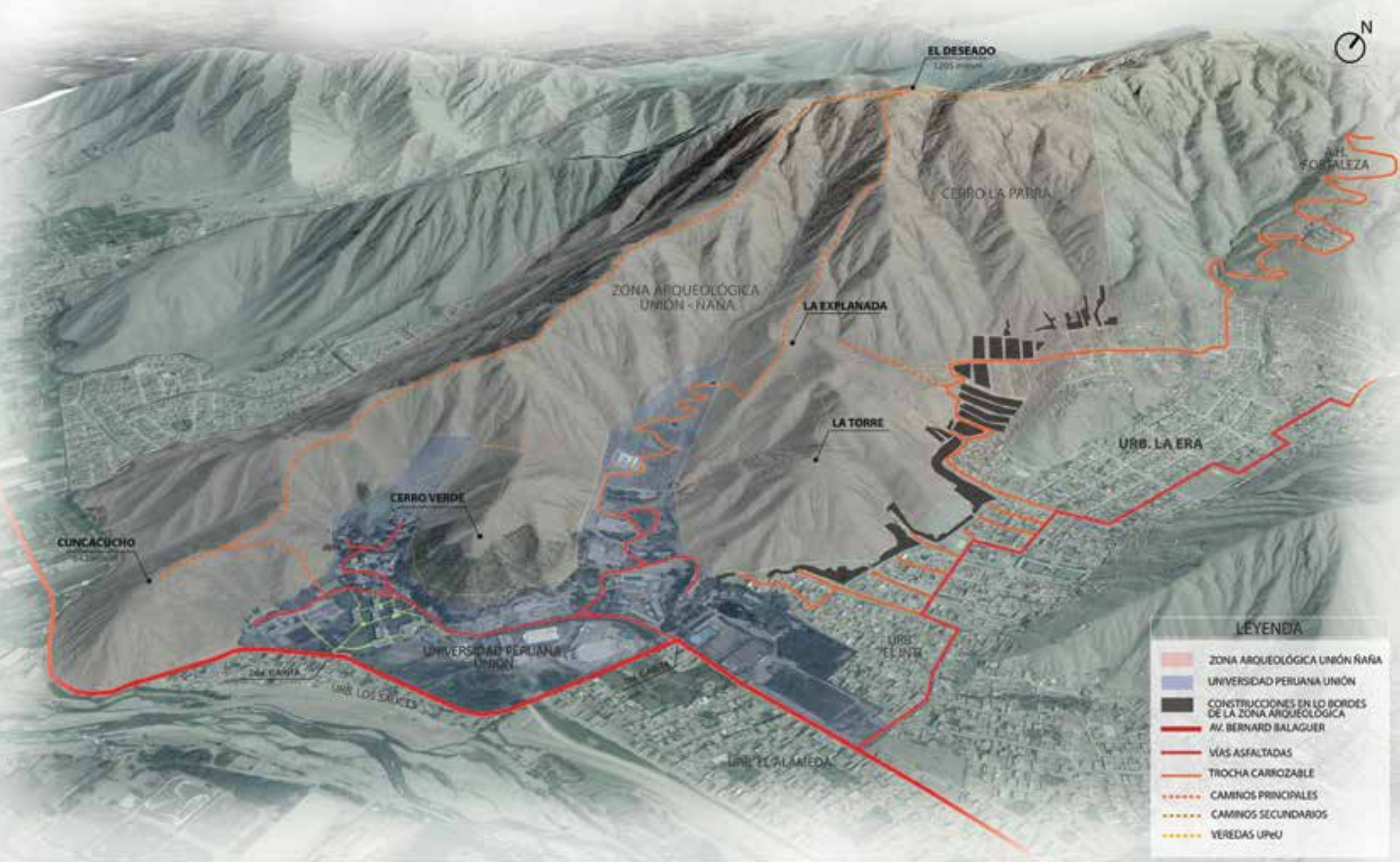

Figura 4. Accesos a zona arqueológica Unión-Naña. Elaborado por J. M. Del Castillo \& P. Sopla, empleando Google Earth, SIGDA, e información levantada en campo por F. Casildo, M. Correa \& K. Delgado, 2018.
El borde entre la universidad y el cerro se ha definido a partir de los edificios que se encuentran alineados con la vía principal del campus y por un muro de pirca que crea una terraza con tratamiento paisajista, salvo en las dos grandes quebradas, Las Tunas y La Mansión, que presentan un acceso directo hacia el entorno montañoso. Desde la localidad de La Era, existen 12 vías transversales al lado este del cerro, de las cuales solo una presenta un acceso libre en la parte más alta, mientras que las 11 restantes tienen como remate una hilera de viviendas que cierra el paso (Figura 4).

Además, durante el estudio realizado, se determinó un área de influencia inmediata a la zona arqueológica y montañosa, conformada por diez zonas aledañas: a) Zona Terrazas, b) Zona 2da Garita, c) Zona UPeU, d) Zona 1era Garita, e) Zona Alameda 1,f) Zona Alameda 2, g) Zona El Inti, h) Lobatón, i) Zona La Era 1 y j) Zona La Era 2. También se constató mediante trabajo de campo los equipamientos comerciales existentes, ya que representan la mayor fuente de trabajo en la zona: tiendas de abarrotes, servicio de copias/Internet, restaurantes, lavanderías, fruterías y librerías (Figura 5).

Finalmente, en cuanto al conocimiento de los vecinos sobre la zona patrimonial, es posible señalar que, si bien es cierto que la población es consciente del significado del concepto de patrimonio cultural y de la existencia de huacas en Ñaña, desconoce que estas se encuentren tan cerca de la UPeU. Sin embargo, el $93 \%$ de los estudiantes encuestados y el $89 \%$ de los vecinos creen en la importancia del desarrollo del patrimonio cultural en la localidad. Además, el estudio permite aseverar que la mayoría con- 


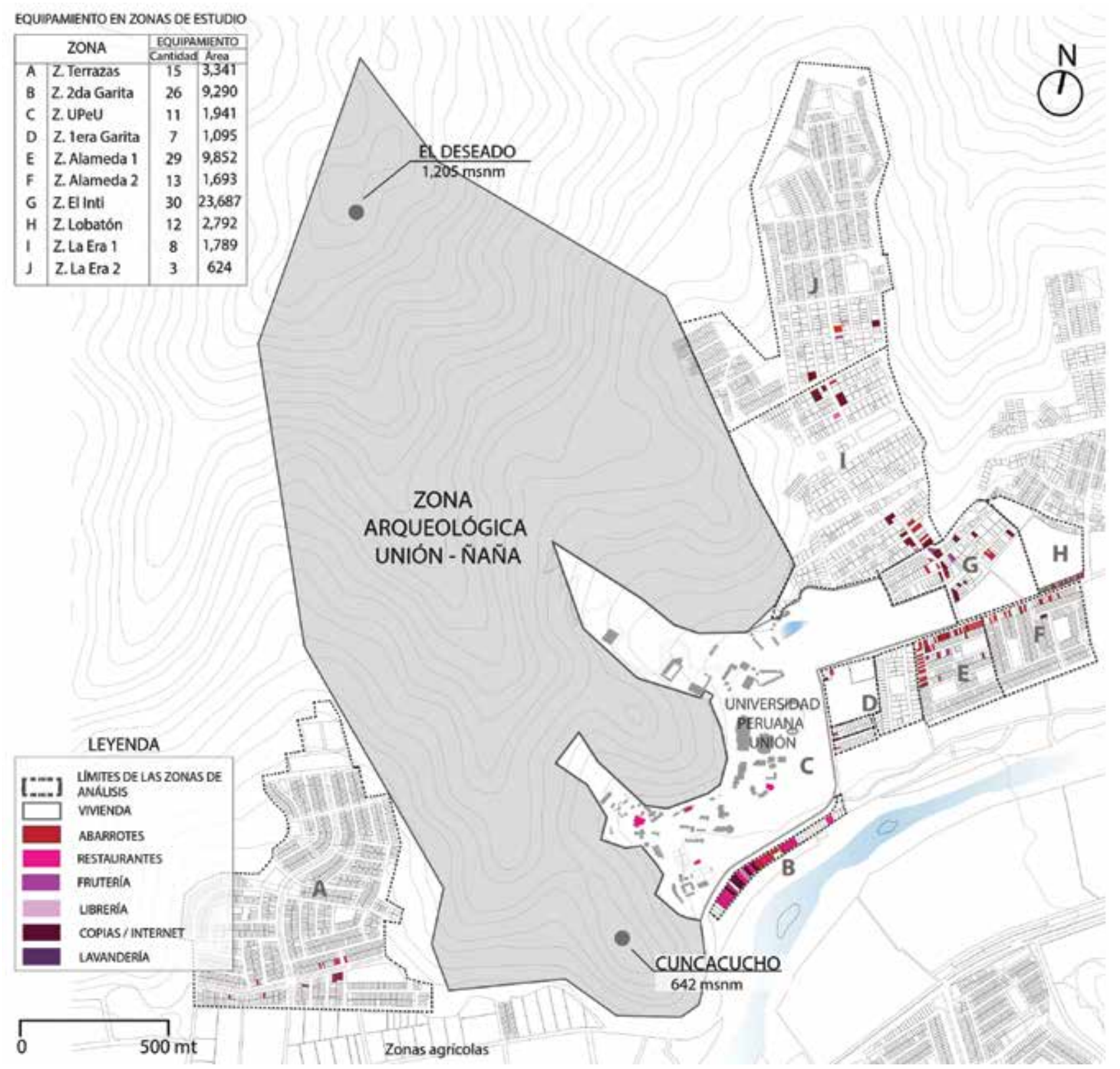

sidera a la falta de difusión como el principal impedimento para el desarrollo cultural de las huacas de Ñaña y que debería ser la UPeU la principal difusora del conocimiento que encierran las áreas patrimoniales de Ñaña. También se plantea que la creación de un centro de investigación y desarrollo podría ayudar a este efecto, ya que si tuvieran la oportunidad de realizar visitas guiadas a estos parajes lo harían.

\section{Consideraciones arqueoastronómicas en el paisaje y patrimonio prehis- pánico de Ñaña}

Debido a su gran extensión, el área arqueológica Unión-Ñaña implicó un arduo trabajo de reconocimiento en campo, y mapeo de sus características geográficas y arquitectónicas. La primera parte de este trabajo se inició en el año 2015, en el Cerro Cuncacucho e inmediaciones, donde se pudo comprobar la existencia de una fortificación con mu-
Figura 5. Uso del suelo en zonas aledañas al área de estudio. Elaborado por J. M. Del Castillo \& P. Sopla, sobre la base de planos de infraestructura UPeU, y estudios de contexto realizados por G. Ballona, J. López, A. Palomino \& C. Vergara, 2018. 
devenir Vol. 5, N¹0, JULIO-DICIEMBRE 2018, PP. 153-174 - EstudIOS I ISSN 2312-7562 I E-ISSN 2616-4949

UNIVERSIDAD NACIONAL DE INGENIERÍ, LIMA

DOI: https://doi.org/10.21754/devenir.v5i10.603

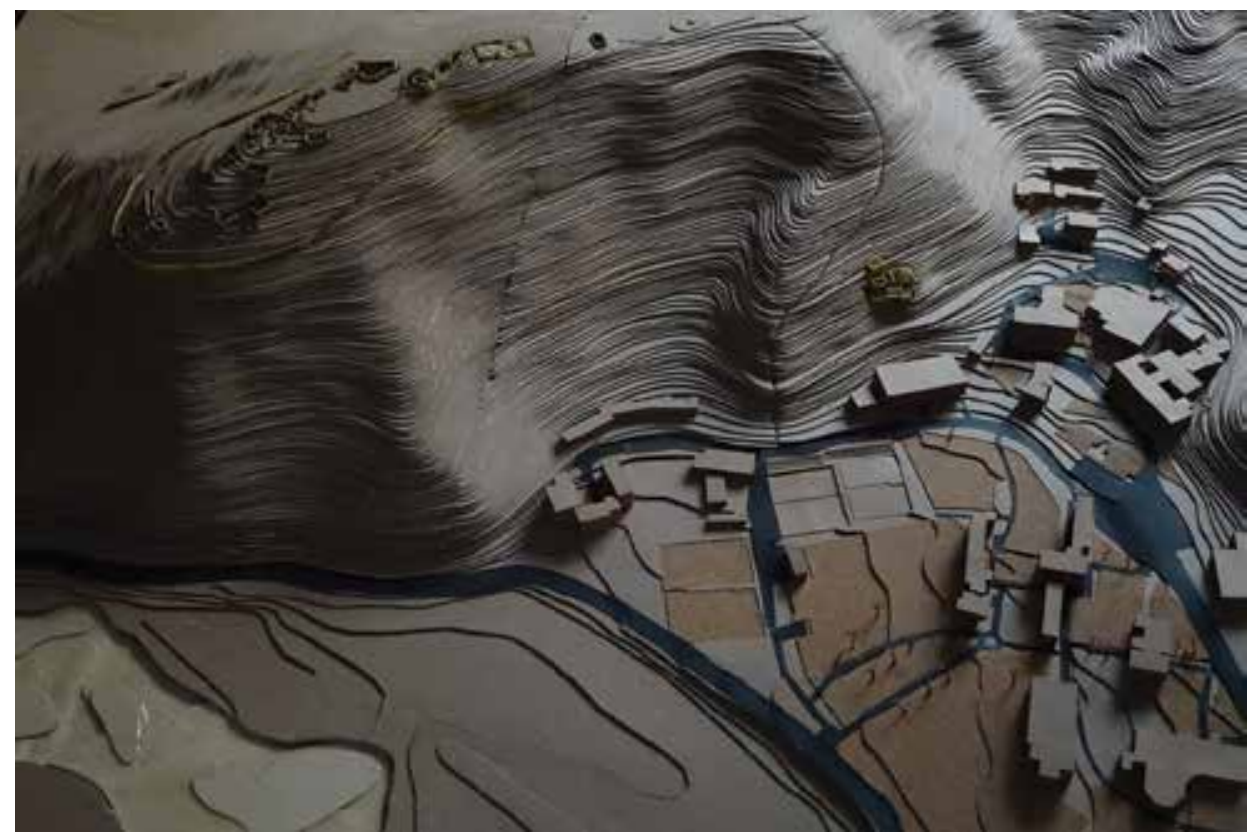

Figura 6. Maqueta del cerro Cuncacucho, con la fortaleza en la cima y el tambo inca al pie, ambos en dorado. Hacia la derecha (en la parte llana) se observan las instalaciones de la UPeU, mientras que en la parte inferior izquierda se ubica el río Rímac. Diseño Arquitectónico IV UPeU, 2015-1, dirigido por J. M. Del Castillo.

ros exteriores (de piedra y tapial) de formas curvas en la cima, que sirvió de residencia para los yañac, además de espacio ritual y administrativo (Palacios, 2013). La abundancia de restos de depósitos para bebidas y alimentos construidos en piedra local, tapial y adobe revela la existencia de un personal permanente al servicio de los señores de estos asentamientos, signo de su importancia. La existencia de plazas tanto interiores como exteriores en el sitio se puede deber a que, al ser los yañac especialistas rituales, y administradores de tierras y acequias, se realizaban actividades relacionadas a estas funciones, que implicaban recibir a grupos humanos numerosos en la cima del cerro.

Asimismo, se pudo comprobar la existencia de un tambo inca, construido enteramente en tapial, en las faldas del cerro Cuncacucho. Al respecto, cabe resaltar que los incas llegaron al valle del Rímac bajo el mando de Túpac Yupanqui, hacia la segunda mitad del siglo XV (Rostworowski, 2013). Estos establecieron un puesto administrativo y de vigilancia en las faldas del cerro, y trasladaron a la población de la cima al llano, cerca de las chacras, para mantenerla controlada. Este modus operandi coincide con la identificación que hace Hyslop de un patrón de asentamiento impuesto en diferentes conquistas incaicas hacia fortificaciones en cimas de cerros (Hyslop, 1990) que, sin embargo, aún no se ha estudiado a profundidad para casos de las regiones chala ( 0 a 500 m s. n. m.) y yunga (500 a 2,300 m s. n. m.) en el Perú (Figura 6).

Hasta julio del año 2016, la investigación se concentró en los restos arqueológicos adyacentes a las instalaciones de la UPeU y su relación con el crecimiento urbano experimentado en Ñaña durante los últimos años. Sin embargo, conocedores de la suma importancia que el papel de la observación astronómica, las peregrinaciones y actividades rituales tenían en el lugar, en adelante la investigación se enfocó en registrar la ruta que unía el asentamiento prehispánico permanente en Cuncacucho con el observatorio estelar ubicado en la cima del cerro La Parra, en la zona conocida como El Deseado.

El área adyacente a este observatorio ancestral ya había sido identificada por Palacios en el Proyecto de Investigación Arqueológica realizado en la zona Unión-Ñaña, 


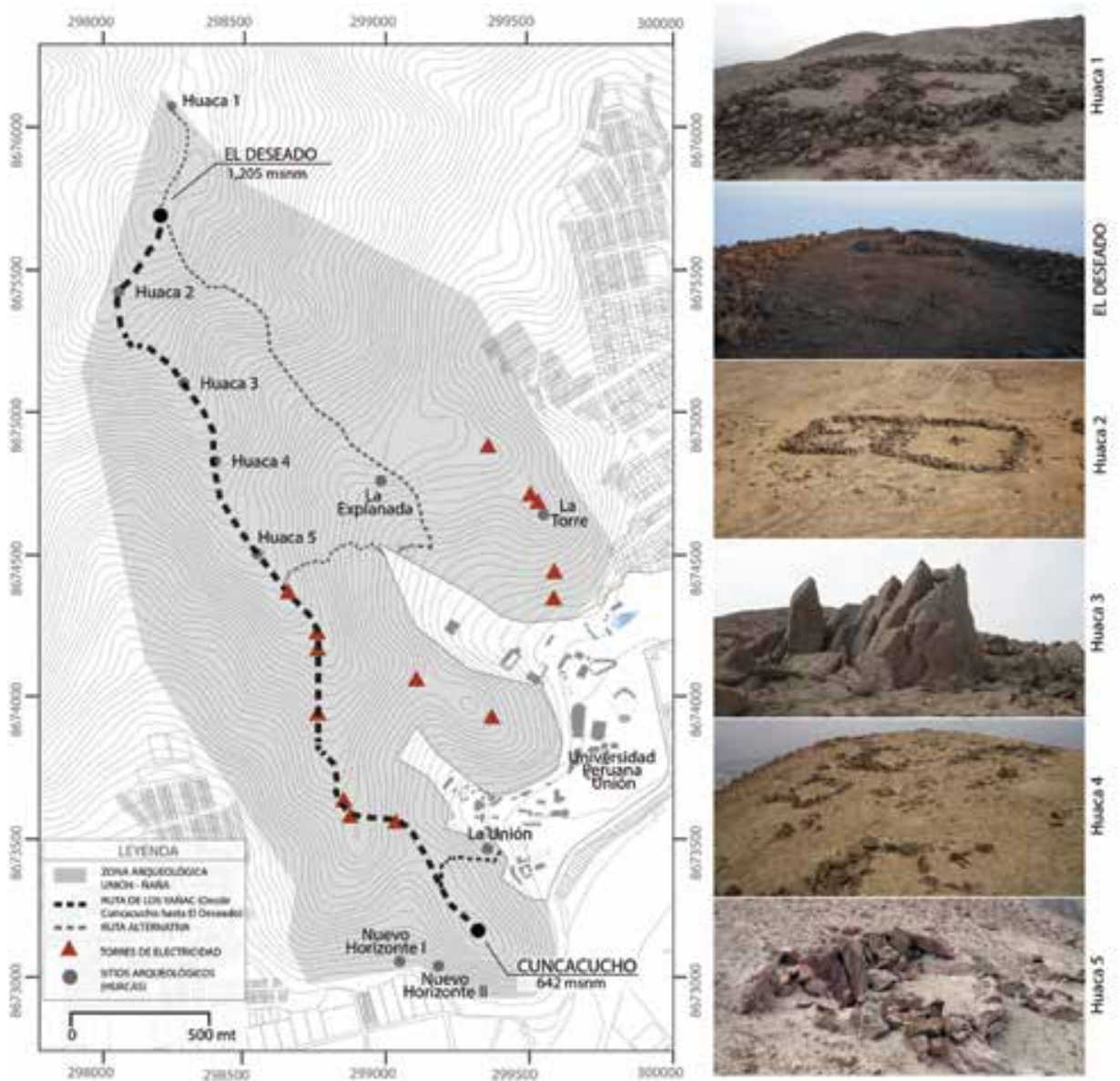

Figura 7. Ruta de los yañac. Elaborado por J. M. Del Castillo \& P. Sopla, sobre la base de planos Infraestructura UPeU, información levantada en campo y fotografías - Huaca 1, 2, 3, 4, 5- por M. Cabezas, K. Mayta, S. Torres \& A. Zúñiga, 2016. Fotografía de El Deseado por P. Sopla.

que permitió comprobar la existencia de estructuras de piedra y geoglifos (Palacios, 2000) relacionados a la observación de los astros durante la noche y las sombras del sol durante el día. Cabe resaltar que la ruta más conocida por los grupos juveniles de exploradores de la comunidad estudiantil de la localidad para acceder a la zona de El Deseado, es escalando a través de la quebrada llamada Las Tunas hacia el lado norte del cerro Cuncacucho, en una caminata de cerca de 3 horas de duración. No obstante, tomando como referencia al Manuscrito de Huarochirí, en el que se explica cómo desde distintas partes de la región se subía hacia la montaña sagrada de los yañac a esperar que estos leyeran en el sol el día de la peregrinación al nevado Pariacaca (Arguedas, 2012), y a las constantes visitas de campo al lugar y sus alrededores, se pudo comprobar la hipótesis de la existencia de una ruta de acceso más directa.

Dicha ruta parte desde la cima del Cuncacucho y luego sigue en línea aproximadamente recta (en planta) hacia el Noroeste, a través de la cresta de los cerros, durante aproximadamente 1 hora y media de caminata hacia la cima El Deseado. Es importante resaltar que, antes de llegar a esta cima, se puede apreciar una zona en la que se ubican una serie de construcciones circulares de piedra, las cuales se encuentran alrededor de una estructura formada por cinco wankas o bloques de piedra ciclópeos, lo cuales parecen haber sido colocados en la zona con finalidad ceremonial y/o astronómica (Palacios, 2017). La forma de esta estructura se asemeja a la cadena de montañas en la 
devenir Vol. 5, N¹0, JULIO - DICIEMBRE 2018, pP. 153-174 - EstudIOS I ISSN 2312-7562 | E-ISSN 2616-4949

UNIVERSIDAD NACIONAL DE INGENIERÍA, LIMA

DOI: https://doi.org/10.21754/devenir.v5i10.603
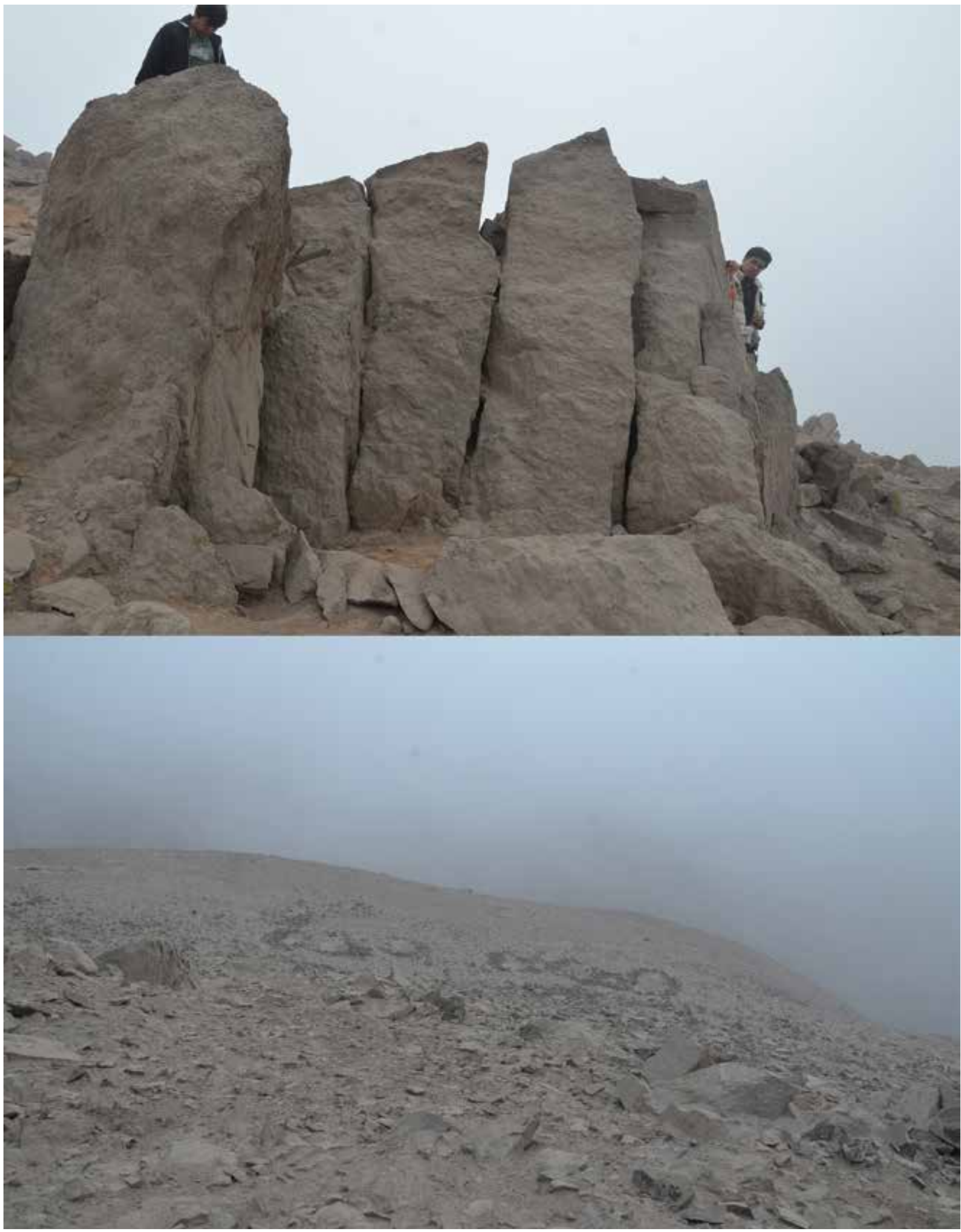

Figura 8. Arriba: Estructura formada por cinco wankas. Abajo: Construcciones circulares de piedra alrededor de las cinco wankas. Archivo personal de J. M. Del Castillo, 2017. 
que se encuentra el apu Pariacaca en las alturas de Huarochirí y Yauyos; y el lugar destacado que ocupa en la distribución espacial de su contexto arquitectónico es muestra de la importancia que debió tener en tiempos prehispánicos. Al seguir subiendo y llegar a la zona de El Deseado, se puede apreciar una extensa explanada con restos de muros en piedra y geoglifos, que hoy se encuentran alterados debido a intervenciones de visitantes esporádicos. Sobre esta explanada se alza un promontorio natural a unos 15 metros más de alto, sobre el cual se encuentra emplazada una construcción de forma ojival de muros de piedra, desde la cual se puede observar la explanada en su totalidad, así como una vista panorámica de todo el Valle del Rímac. Por encontrarse a 1,205 m s. n. m., por encima de la capa de nubes que cubre a Lima, esta construcción ojival supone una posición privilegiada para la observación de los astros, las montañas de Huarochirí hacia el Este, la costa del Callao hacia el Oeste y la cadena de montañas que forma el valle del Chillón hacia el Norte. Dadas las características de este espacio, se decidió realizar trabajo de campo nocturno en el lugar para comprobar su importancia como observatorio astronómico (ver Figuras 7 y 8 ).

Junto a un equipo de investigación conformado por estudiantes y docentes de la escuela de Arquitectura UPeU se escogió la madrugada entre el día 31 de octubre y el 1 de noviembre de 2016 para pernoctar en el lugar, una fecha importante en el calendario andino prehispánico, que indica el inicio de las celebraciones de Aya Marcay Quilla o mes/fiesta de los difuntos (Arce, Julca \& Limay, 2005). Alrededor de las 03:30 a.m. del 1 de noviembre de 2016 se pudo comprobar la calidad del lugar como punto de observación astronómica, pues fue posible obtener un claro registro de la Vía Láctea en toda su inmensidad, así como de otras constelaciones importantes para el mundo andino como Chakana (Cruz del Sur), Orión, Catachillay (Pléyades), y la presencia de múltiples estrellas fugaces. Cerca de las 5:00 a.m. del mismo día, el brillo especialmente intenso del planeta Júpiter (Phirwa en quechua, benefactor de la agricultura) (Salazar, 2014) hacia el Este, alineado verticalmente con las montañas de Huarochirí y el resplandor inusual sobre una de estas, llevó al equipo de investigadores a generar la hipótesis de que en esa dirección se hallaba una posible alineación astronómica con algún sitio prehispánico sagrado y/o de peregrinación. Además, dada la importancia de la observación solar para los yañac, se decidió corroborar si la fecha en que el amanecer se alinea con Ñaña y Pariacaca coincidía con una fiesta importante del calendario andino.

Para esta parte del trabajo se consideró la importancia que las relaciones cósmicas tenían en la cosmovisión del hombre andino prehispánico. Por ejemplo, estas están presentes en los relatos de origen incaicos: es Inti (el padre Sol) quien envía a sus hijos a cumplir misiones fundacionales, mientras que Quilla (la madre Luna) es la progenitora de todas las estrellas (Salazar, 2014). Así mismo, durante la formulación de la hipótesis se consideró la importancia que el sistema de ceques incas (líneas de energía o "ríos de estrellas"), que conectaban a todas las huacas del Tawantinsuyu con el Templo del Sol (Bauer, 1998), tenían en la organización territorial del imperio, y el Qhapaq Ñan o gran red de caminos.

Luego de todas estas consideraciones y de contrastar los apuntes de campo con imágenes satelitales, software astronómico (Stellarium y SunCalc) y mapas geo referenciados (elaborados con ARC GIS) se postuló que, en primer lugar, el observatorio astronómico de Ñaña se conecta con el pico sur de la montaña sagrada Sucyahuillca, en las alturas de Huarochirí, a través de una línea recta imaginaria (a $\left.90^{\circ}\right)$ trazada hacia el Este. Esta línea cruza a su vez por distintos puntos de interés histórico antes de llegar a Sucyahuillca, la mayoría mencionados en el Manuscrito de Huarochirí, entre los que destaca la quebrada California, en Chaclacayo. En segundo lugar, se comprobó también que el día 26 de septiembre de 2016 el sol se alinea al amanecer con el Pariacaca y con el observatorio El Deseado en Ñaña, por lo que se postula que una de las posibles fechas en que los yañac lideraban una de las tres peregrinaciones anuales que se hacían hacia el Pariacaca era alrededor del equinoccio de primavera (ver Figuras 9,10 y 11). 

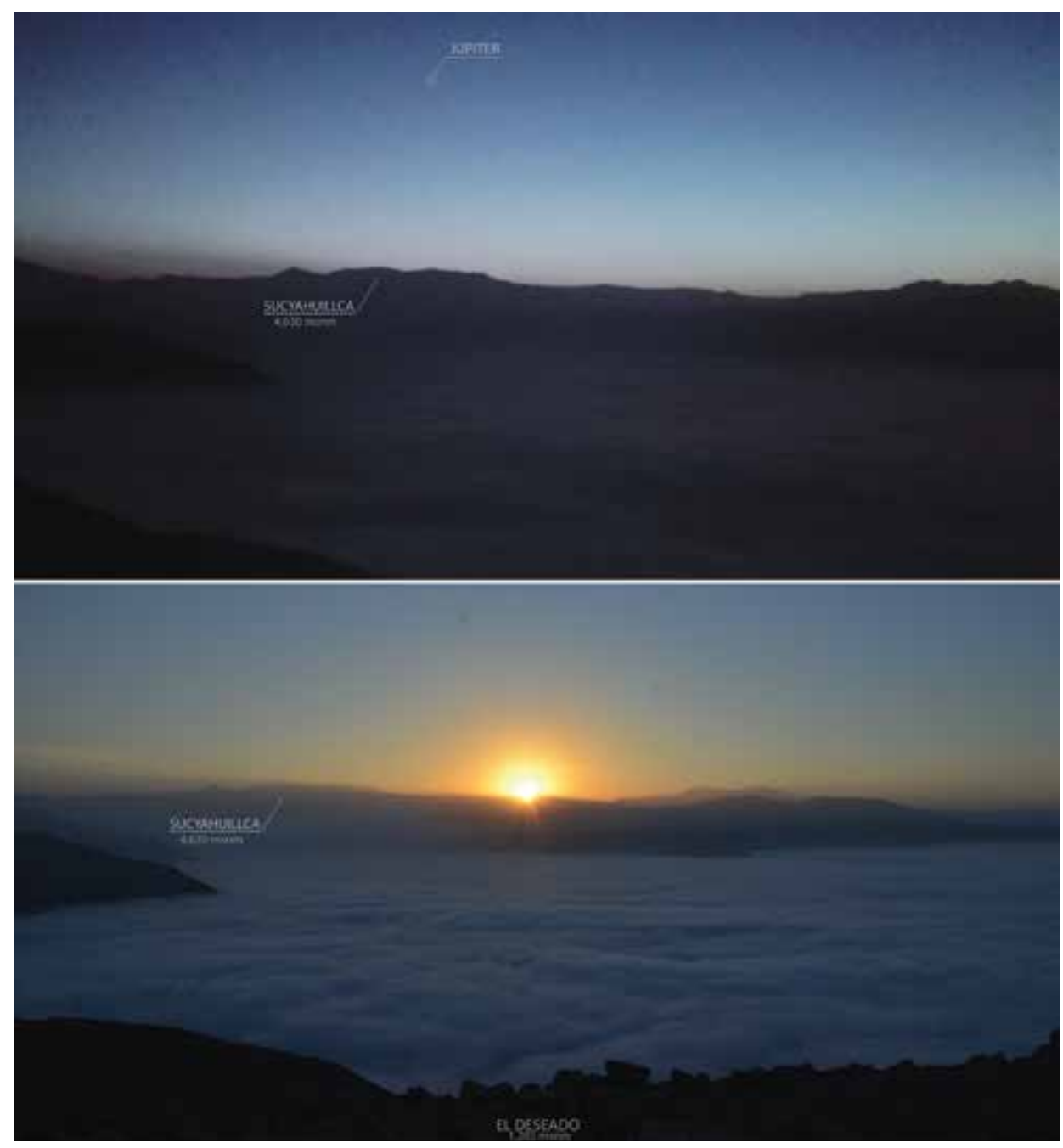

Figura 9. Arriba: Alineación vertical de Júpiter y Sucyahuillca a las 5:00 a.m. del 01 de noviembre de 2016. Abajo: Posición del sol tras las montañas de Huarochirí al amanecer del mismo día (5:48 a.m.). Vistas desde el observatorio de El Deseado. Archivo fotográfico de J. M. Del Castillo.

En la quebrada California se encuentra el inicio de un elaborado tramo del Camino Inca, construido en piedra, que conecta el valle del río Rímac con el valle del río Lurín (quebrada de Chontay), que aún se conserva en su mayor parte. Esta bien acabada obra de ingeniería inca se une a su vez al mítico tramo mayor Xauxa-Pachacamac del Qhapaq Ñan, que unía los santuarios de Pachacámac en la costa y Pariacaca en la sierra de Lima (Casaverde Ríos, 2017), y que era una de las rutas de peregrinaje más importantes del mundo andino.

Por otro lado, la montaña blanca Sucyahuillca, entre las alturas de la actual localidad de San Andrés de Tupicocha en Huarochirí, es considerada un apu menor (hermano de Pachacámac), al que los naturales subían en tiempos prehispánicos a pedir la llegada de la lluvia en tiempos de sequía, con ofrendas de oro y plata. Así mismo, en el Manuscrito de Huarochirí, se le señala como lugar donde pastaban las llamas de Pachacámac, las cuales eran cuidadas por los descendientes de Tutayquiri (hijo de Pariacaca). Casualmente, parte del culto a Tutayquiri, que tiene lugar durante el mes de noviembre, se llevaba a cabo debajo de Sucyahuillca, hacia San Andrés de Tupicocha, en un lugar llamado Mayani (Taylor, 2008). Las imágenes satelitales revelan la existencia de restos de cons- 


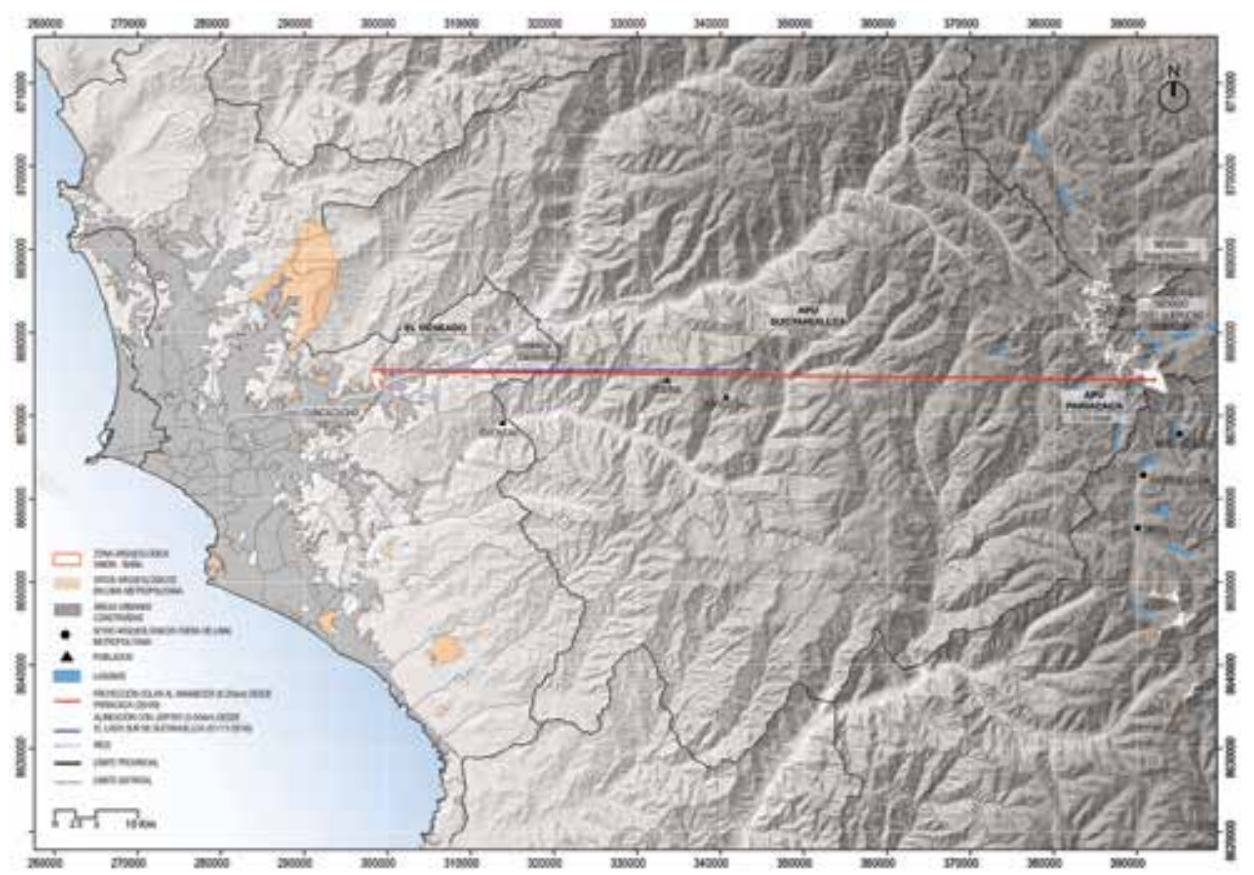

Figura 10. Mapa de alineaciones astronómicas de Ñaña con los apus Sucyahuillca y Pariacaca. Elaborado por J. M. Del Castillo \& P. Sopla sobre la base de archivos shapefile-ArcGIS del Ministerio de Cultura y el Instituto Geográfico Nacional, 2018.

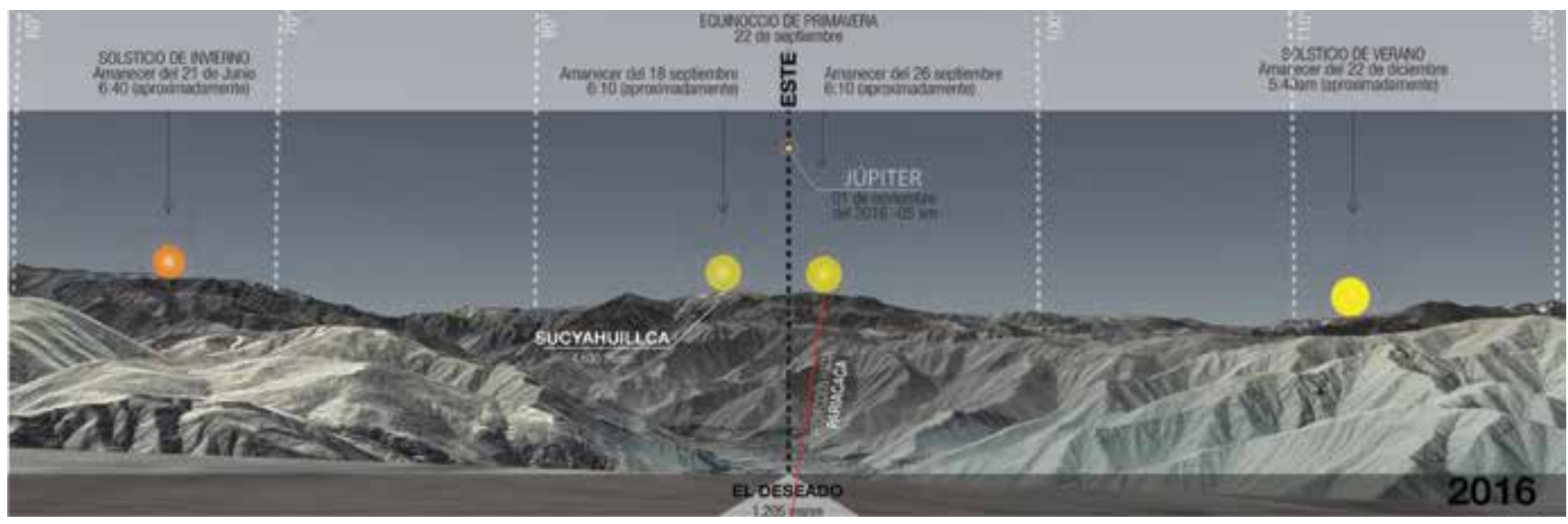

Figura 11. Comprobación de alineaciones astronómicas en Ñaña con programas Stellarium, SunCalc y Google Earth. Elaborado por J. M. Del Castillo \& P. Sopla, 2018.

trucciones con probable valor arqueológico en la cima de Sucyahuillca, que deben ser analizados mediante trabajo de campo en la zona, ya que no existen estudios previos.

La hipótesis del alineamiento entre Ñaña y estas dos montañas sagradas demostraría que el primero es uno de los observatorios estelares más importantes del valle del Rímac. Esto debe comprobarse con un estudio más especializado del sistema de alineamientos astronómicos y asentamientos en la región del Rímac y Huarochirí. Es importante entender que los andinos prehispánicos eran diestros astrónomos y creían que todo estaba escrito en el firmamento, hecho que incluso fue admitido por los primeros cronistas invasores de esas tierras (Cieza de León, 1984), que la mayor parte 
devenir Vol. 5, N¹0, JULIO-DICIEMBRE 2018, PP. 153-174 - EstUDIOS I ISSN 2312-7562 | E-ISSN 2616-4949

UNIVERSIDAD NACIONAL DE INGENIERÍA, LIMA

DOI: https://doi.org/10.21754/devenir.v5i10.603

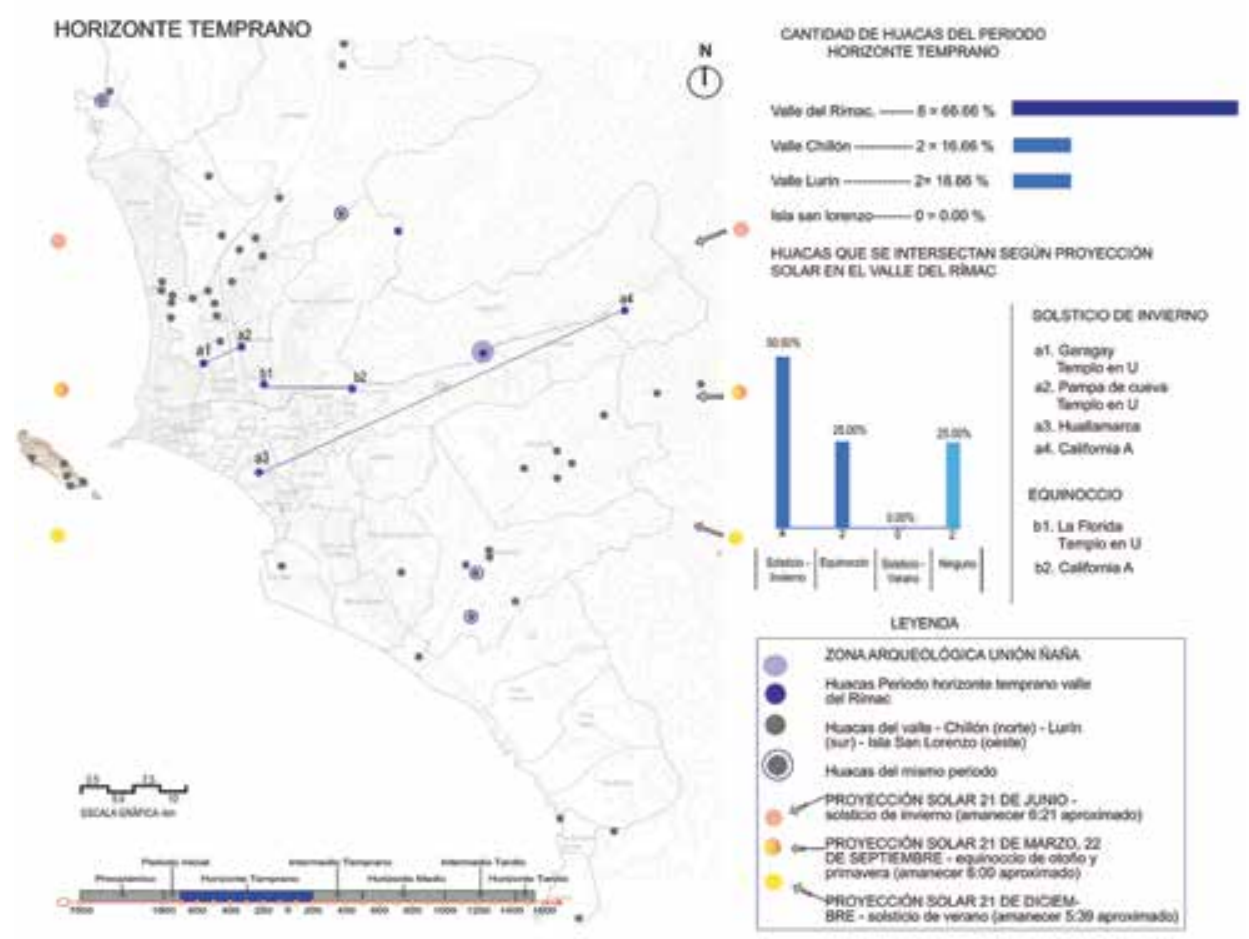

Figura 12. Posibles alineamientos astronómicos (según la proyección solar al amanecer) entre asentamientos del periodo Horizonte Temprano en el valle del Rímac. Elaborado por P. Sopla a partir del plano Huacas, por la Municipalidad Metropolitana de Lima, 2014; y el trabajo de análisis de M. Carrasco, P. Sopla \& G. Tafur, 2018.

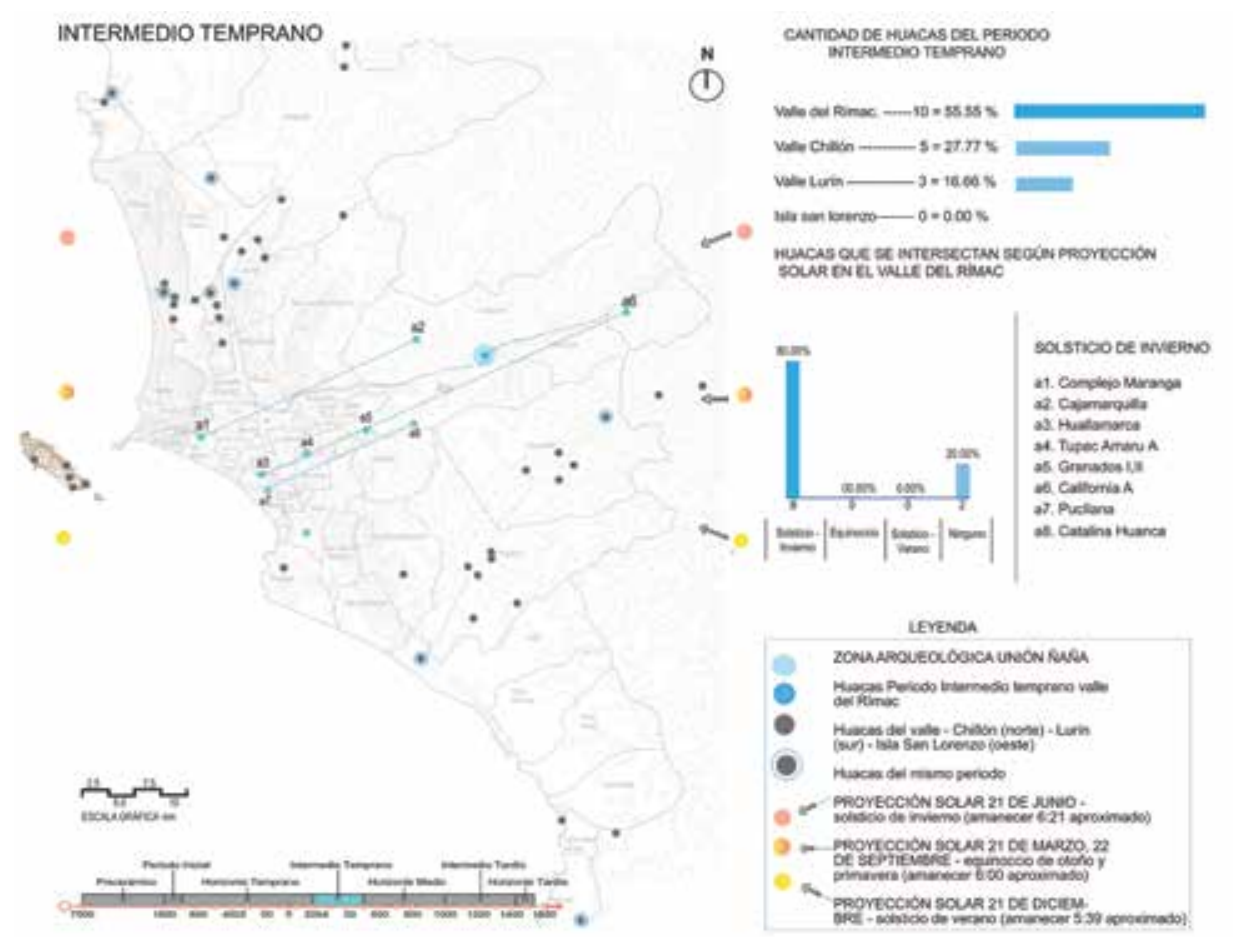

Figura 13. Posibles alineamientos astronómicos (según la proyección solar al amanecer) entre asentamientos del periodo Intermedio Temprano en el valle del Rímac. Elaborado por P. Sopla a partir del plano Huacas, por la Municipalidad Metropolitana de Lima, 2014; y el trabajo de análisis de M. Carrasco, P. Sopla \& G. Tafur, 2018. 


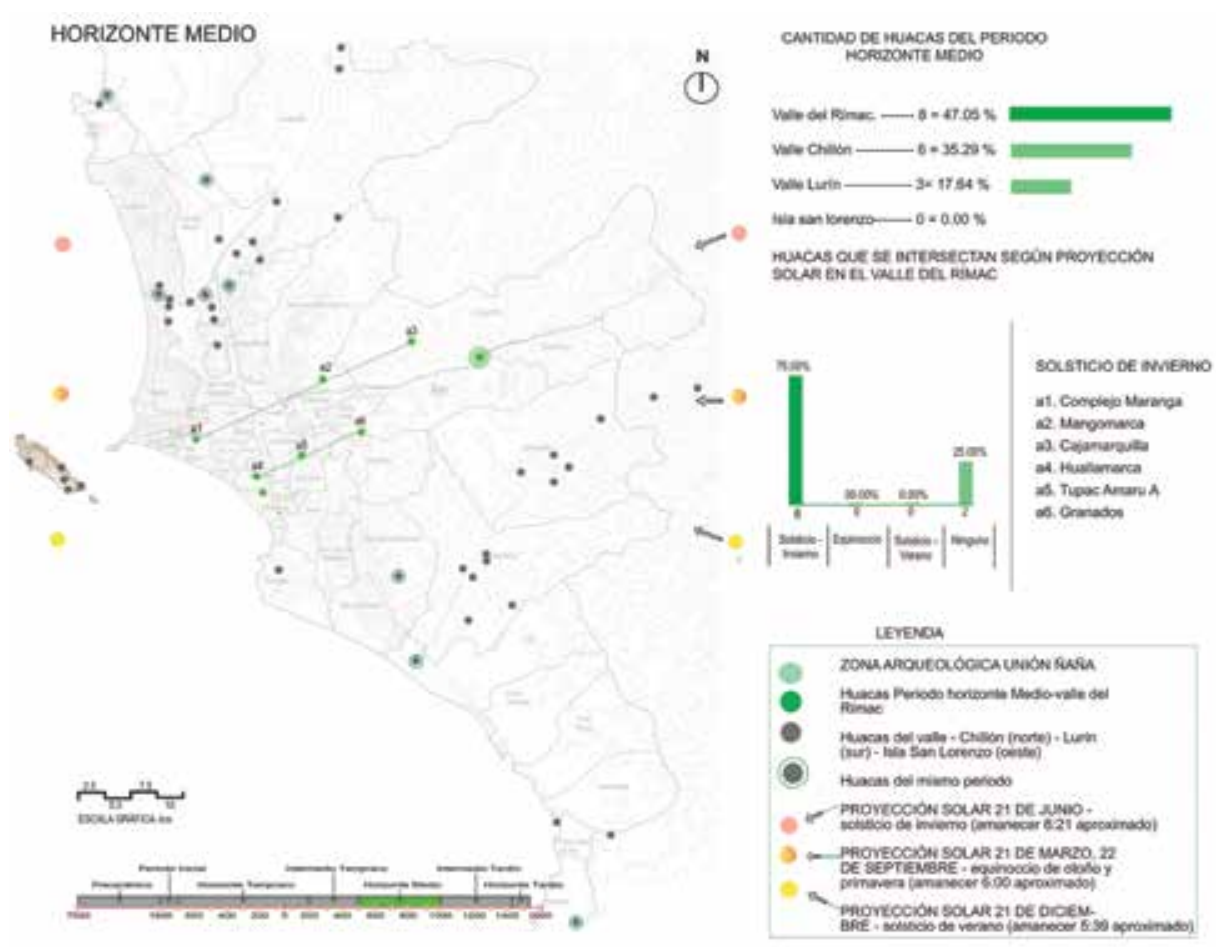

Figura 14. Posibles alineamientos astronómicos (según la proyección solar al amanecer) entre asentamientos del periodo Horizonte Medio en el valle del Rímac. Elaborado por P. Sopla a partir del plano Huacas, por la Municipalidad Metropolitana de Lima, 2014; y el trabajo de análisis de M. Carrasco, P. Sopla \& G. Tafur, 2018.

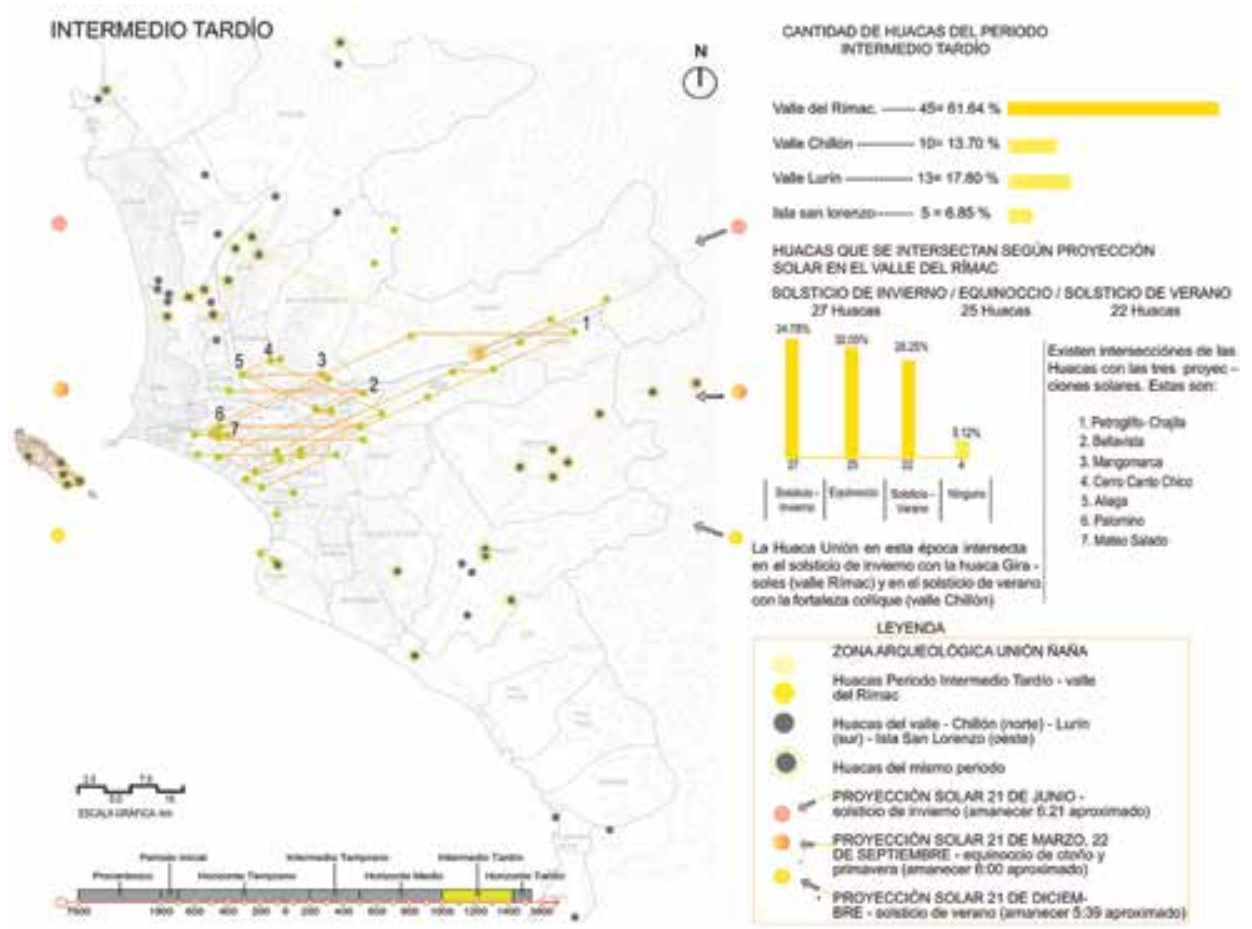

Figura 15. Posibles alineamientos astronómicos (según la proyección solar al amanecer) entre asentamientos del periodo Intermedio Tardío en el valle del Rímac. Elaborado por P. Sopla a partir del plano Huacas, por la Municipalidad Metropolitana de Lima, 2014; y el trabajo de análisis de M. Carrasco, P. Sopla \& G. Tafur, 2018. 
de las veces no entendían los avanzados conocimientos que los antiguos peruanos tenían del cosmos. Por ello no causa sorpresa que, al mapear los asentamientos prehispánicos por periodo temporal, a escala regional, se pueda encontrar muchas posibles relaciones territoriales entre estos si se toma en cuenta los solsticios de verano e invierno, y los equinoccios (ver Figuras 12, 13, 14 y 15).

Como se puede apreciar, las posibilidades que la consideración de la variable arqueoastronómica abre para la comprensión del patrimonio prehispánico constituyen un espacio fértil, aún por explorar. Los alcances del presente estudio son resultado del uso eficiente de los recursos disponibles; sin embargo, como se señaló antes, es necesario analizar con mayor detalle y mediante esfuerzos multidisciplinarios los alineamientos astronómicos en relación a la arquitectura prehispánica y el paisaje de la margen derecha del valle de Rímac, aún muy poco estudiados hasta el día de hoy.

\section{Conclusiones}

El paisaje prehispánico intersticial de Ñaña es testimonio de cerca de 4,000 años de ocupación territorial del hombre andino en el valle medio del río Rímac. Constituye un caso representativo del cuantioso patrimonio natural y cultural que Lima alberga en sus bordes metropolitanos. El atractivo ecológico de sus cerros, que aún conservan vegetación y fauna típicas de lomas costeras extraordinarias, se ha visto sin embargo afectado por el crecimiento urbano sin planificación que ha tenido lugar en los alrededores durante los últimos 20 años, así como por proyectos de reforestación realizados sin el debido asesoramiento.

Debido a su ubicación estratégica, la UPeU no solo ha servido como protección para la zona arqueológica Unión-Ñaña ante los conflictos territoriales que tienen lugar en estos intersticios urbanos (producto de la tensión entre el avance informal de la periferia urbana sobre los remanentes de áreas rurales y patrimoniales), sino que también ha permitido el uso de los cerros aledaños como áreas recreativas por parte de la comunidad estudiantil. Así mismo, la universidad promueve la investigación de este paisaje prehispánico desde hace dos décadas.

Los parajes y huacas ubicados en las cimas de estos cerros sirven de espléndidos puntos de observación astronómica, debido a su posición elevada (1,205 m s. n. m.) sobre el manto de nubes blancas que cubre a Lima durante la mayor parte del año y no permite observar las estrellas libremente. Estos constituyen un patrimonio arqueoastronómico valioso, asociado a los yañac y a la información recogida en el Manuscrito de Huarochirí. Su importancia pudo ser comprobada mediante trabajo de campo nocturno, lo que a su vez llevó a la formulación de la hipótesis de la existencia de dos alineaciones astronómicas entre el observatorio prehispánico de El Deseado, en la cima del cerro La Parra, y las montañas sagradas o apus de Huarochirí y Yauyos. La primera de estas alineaciones se observó entre Júpiter, el apu Sucyahuillca y El Deseado a las 5:00 a.m. del 1 de noviembre de 2016 (Aya Marcay Quilla); y la segunda, entre el Sol, el apu Pariacaca y El Deseado, alrededor de las 6:00 a.m. del 26 de setiembre del mismo año (equinoccio de primavera). Esta última alineación permite suponer que los yañac lideraban peregrinaciones hacia el Pariacaca alrededor de esas fechas. De comprobarse la hipótesis de estos dos alineamientos, se demostraría que Ñaña posee uno de los observatorios astronómicos prehispánicos más importantes del Valle del Rímac.

Estos resultados revelan la importancia de ahondar en lecturas multidisciplinarias de las narraciones sagradas de la cosmovisión andina (como aquellas contenidas en el Manuscrito de Huarochiri), y su relación con el paisaje de esta localidad y el valle que la alberga. Así, se reivindica una visión del patrimonio que va más allá del objeto arquitectónico y/o arqueológico, y trasciende hacia la escala del paisaje, lo cual permite tener un mejor entendimiento del rol de estos sitios en el manejo del territorio y la predicción de fenómenos climáticos en tiempos prehispánicos. 
La diversidad de posibilidades y temáticas que los resultados implican para el futuro estudio de estos parajes es prueba clara de la necesidad de nuevas investigaciones que expandan los alcances de la presente, y puedan servir como base para elaborar futuras políticas de desarrollo ambiental y cultural en los paisajes prehispánicos en los bordes metropolitanos de Lima, como el de Ñaña.

\section{Referencias}

Aguilar, P., \& Turkowsky, J. (1977). Fauna Desértico-Costera Peruana - III: Observaciones en el Tillandsial de Cajamarquilla, Lima. Homenaje a la Universidad Nacional Agraria, 20(1), 81-85.

Arce, M.; Julca, T.; \& Limay, L. (2005). Culto andino a los muertos en los cementerios de Lima Metropolitana. Aportes Estudiantiles. Revista de Antropología, 3(3), 323-332.

Arguedas, J. M. (2012). Dioses y hombres de Huarochirí: Narración quechua recogida por Francisco de Ávila. Lima, Perú: Instito de Estudios Peruanos.

Astete Victoria, F.; Ziółkowski, M.; \& Kościuk, J. (2017). On Inca astronomical instruments: The observatory at Inkaraqay - El Mirador (National Archaeological Park of Machu Picchu, Peru). Estudios Latinoamericanos, Vol. 36/37, 9-25.

Bauer, B. (1998). The sacred landscape of the Incas: The Cusco ceque system. Austin: University of Texas Press.

Canziani, J. (2009). Ciudad y territorio en los Andes: Contribuciones a la historia del urbanismo prehispánico. Lima: Pontificia Universidad Católica del Perú.

Casaverde Ríos, G. (2017). Definiendo la cronología relativa en los caminos: El camino del Pariacaca. Boletín del Museo Chileno de Arte Precolombino, 65-81.

Castillo, R. (2010). La mano de Dios en la educación adventista del Perú: Breve historia de la creación de la UPeU. Lima, Perú: Universidad Peruana Unión.

Cieza de León, P. (1984). La crónica del Perú. Madrid, España: Historia 16.

Del Castillo, J. M. (2015). Lima Biotopo: Ecosistemas de montaña, patrimonio arqueológico indígena y activismo en los intersticios urbanos de la megalópolis andina. VII Seminario Internacional de Investigación en Urbanismo. Universidad de la República de Uruguay, Montevideo; Universidad Politénica de Barcelona, España. Recuperado de https://upcommons.upc.edu/ handle $/ 2117 / 80488$ ?show=full

Del Castillo, J. M. (1 de febrero de 2016). Espacios abiertos y patrimonio arquitectónico originario en Ñaña. Arkinka, (243), 86-93.

Gandy, M. (2011). Interstitial Landscapes: Reflections on a Berlin corner. En M. Gandy, Urban constellations (pp. 149-153). Berlín, Alemania: Jovis.

Ghezzi, I., \& Ruggles, C. (2006). Las trece torres de Chankillo: Arqueoastronomía y organización social en el primer observatorio solar de América. Boletín de Arqueología PUCP, 215-235.

Ghezzi, I., \& Ruggles, C. (2007). Chankillo: A 2300-Year-Old Solar Observatory in Coastal Peru. Science, 315, 1239-1243.

Giovannetti, M. A. (2015). Fiestas y ritos inka en El Shincal de Quimivil: la presencia del Tawantinsuyu en la provincia de Catamarca. Buenos Aires, Argentina: Punto de Encuentro.

Guzmán Requena, N. (18 de enero de 2018). MEMORANDO N000009-2018/DMO/DGPA/VMPCIC/ MC. Lima: Ministerio de Cultura del Perú.

Hayakawa, J. (2010). Gestión del patrimonio cultural y centros históricos latinoamericanos: Tendiendo puentes entre el patrimonio y la ciudad. Lima, Perú: Universidad Nacional de Ingeniería.

Hyslop, J. (1990). Inka settlement planning. Austin: University of Texas Press.

Jorgensen, A., \& Tylecote, M. (2007). Ambivalent landscapes - wilderness in the urban interstices. Landscape Research, 443-462.

McKim Malville, J. (2011). Astronomy and ceremony at Chankillo. En "Oxford IX" International Symposium on Archaeoastronomy. Proceedings IAU Symposium No. 278 (pp. 154-161). Lima, Perú: International Astronomical Union. 
devenir Vol. 5, N¹0, JULIO-DICIEMBRE 2018, PP. 153-174 - EstUDIOS I ISSN 2312-7562 | E-ISSN 2616-4949 UNIVERSIDAD NACIONAL DE INGEEIERÍA, LIMA

DOI: https://doi.org/10.21754/devenir.v5i10.603

Municipalidad Metropolitana de Lima. (2014). Plan Metropolitano de Desarrollo Urbano Lima y Callao 2035. Lima, Perú: Autor.

Nilon, C. H.; Berkowitz, A. R.; \& Hollweg, K. S. (2003). Introduction: Ecosystem Understanding Is a Key to Understanding Cities. En C. H. Nilon, A. R. Berkowitz, \& K. S. Hollweg, Understanding urban ecosystems: A new frontier for science and education (pp. 1-14). New York: Springer.

Padilla, D. (2012). Lomas de Mangomarca, Campoy y El Sauce: Estudio de caso. Lima, Perú: Ministerio del Ambiente.

Padilla, D. (2017). Estudio de la variación espacio-temporal de la comunidad vegetal de las Lomas de Mangomarca durante el año 2013 como contribución a su gestión. Lima, Perú: Universidad Nacional Agraria La Molina.

Palacios, J. (2000). Proyecto Arqueológico Unión-Ñaña: Informe final. Lima, Perú: Instituto Nacional de Cultura.

Palacios, J. (2013). La fortaleza del Cerro Cuncacucho: Ñaña, valle medio del Rímac. Lima, Perú: Universidad Peruana Unión.

Palacios, J. (2017). Agua. Ritual y culto en yañac (Ñaña): La montaña sagrada. Lima, Perú: Universidad Peruana Unión.

Presidencia de la República. (23 de setiembre de 2015). Decreto Legislativo № 1202. El Peruano, 561976.

Rostworowski, M. (1990). Tasa y tributo del curacazgo de Lima, 1549. Historia y cultura, (18), 110113.

Rostworowski, M. (2013). Historia del Tahuantinsuyu. Lima, Perú: Instituto de Estudios Peruanos.

Salazar, E. (2014). Astronomía inka: Arqueoastronomía y etnoastronomía. Lima, Perú: Museo Andrés Del Castillo.

Silva, C. (2017). The Interstitial Spaces of Urban Sprawl. Understanding the Components of the Unbuilt Suburban Geography of Santiago de Chile. Io Squaderno 46: Suburbs and Interstices, 7-12.

Szlavecz, K.; Warren, P.; \& Pickett, S. (2011). Biodiversity on the Urban Landscape. Human population. Ecological studies (Analysis and synthesis), 214, 75-101.

Taylor, G. (2008). Ritos y tradiciones de Huarochiri. Lima, Perú: Instituto Francés de Estudios Andinos.

Zeballos, H.; Villegas, L.; Gutiérrez, R.; Caballero, K.; \& Jiménez, P. (2000). Vertebrados de las Lomas de Atiquipa y Mejúa, Sur del Perú. Revista de Ecología Latinoamericana, 11-18. 